\title{
Article
}

\section{The Sodium-Glucose Cotransporter-2 Inhibitor Canagliflozin Alleviates Endothelial Dysfunction Following In Vitro Vascular Ischemia/Reperfusion Injury in Rats}

\author{
Sevil Korkmaz-Icöz ${ }^{1, *}$, Cenk Kocer ${ }^{1}$, Alex A. Sayour ${ }^{1,2}$, Patricia Kraft ${ }^{1}$, Mona I. Benker ${ }^{1}$, Sophia Abulizi ${ }^{1}$, \\ Adrian-Iustin Georgevici ${ }^{3}{ }^{-}$, Paige Brlecic ${ }^{1}$, Tamás Radovits ${ }^{2}$, Sivakkanan Loganathan ${ }^{1,4}$, Matthias Karck ${ }^{1}$ \\ and Gábor Szabó ${ }^{1,4}$
}

check for

updates

Citation: Korkmaz-Icöz, S.; Kocer, C.; Sayour, A.A.; Kraft, P.; Benker, M.I.; Abulizi, S.; Georgevici, A.-I.; Brlecic, P.; Radovits, T.; Loganathan, S.; et al. The Sodium-Glucose Cotransporter-2 Inhibitor Canagliflozin Alleviates Endothelial Dysfunction Following In Vitro Vascular Ischemia/Reperfusion Injury in Rats. Int. J. Mol. Sci. 2021, 22, 7774. https://doi.org/10.3390/ ijms 22157774

\section{Academic Editor:}

Anastasios Lymperopoulos

Received: 7 July 2021

Accepted: 15 July 2021

Published: 21 July 2021

Publisher's Note: MDPI stays neutral with regard to jurisdictional claims in published maps and institutional affiliations.

Copyright: (c) 2021 by the authors. Licensee MDPI, Basel, Switzerland. This article is an open access article distributed under the terms and conditions of the Creative Commons Attribution (CC BY) license (https:/ / creativecommons.org/licenses/by/ $4.0 /)$
1 Department of Cardiac Surgery, University Hospital Heidelberg, 69120 Heidelberg, Germany; cenk.kocer@web.de (C.K.); alexali.sayour@gmail.com (A.A.S.); kraft@uni-heidelberg.de (P.K.); m.i.benker@t-online.de (M.I.B.); sophiaabulizi@yahoo.de (S.A.); paigebrlecic@yahoo.com (P.B.); sivakkanan@gmail.com (S.L.); matthias.karck@med.uni-heidelberg.de (M.K.); Gabor.Szabo@uk-halle.de (G.S.)

2 Heart and Vascular Center, Semmelweis University, 1122 Budapest, Hungary; radovitstamas@yahoo.com

3 Department of Anesthesiology, St. Josef Hospital, Ruhr-University Bochum, 44791 Bochum, Germany; igeorgevici@outlook.com

4 Department of Cardiac Surgery, University Hospital Halle (Saale), 06120 Halle, Germany

* Correspondence: korkmaz@uni-heidelberg.de; Tel.: +49-6221-566246; Fax: +49-6221-564571

Abstract: Vascular ischemia/reperfusion injury (IRI) contributes to graft failure and adverse clinical outcomes following coronary artery bypass grafting. Sodium-glucose-cotransporter (SGLT)-2inhibitors have been shown to protect against myocardial IRI, irrespective of diabetes. We hypothesized that adding canagliflozin (CANA) (an SGLT-2-inhibitor) to saline protects vascular grafts from IRI. Aortic rings from non-diabetic rats were isolated and immediately mounted in organ bath chambers (control, $\mathrm{n}=9-10$ rats) or underwent cold ischemic preservation in saline, supplemented either with a DMSO vehicle (IR, $\mathrm{n}=8-10$ rats) or 50 $\mu$ M CANA (IR + CANA, $\mathrm{n}=9-11$ rats). Vascular function was measured, the expression of 88 genes using PCR-array was analyzed, and feature selection using machine learning was applied. Impaired maximal vasorelaxation to acetylcholine in the IR-group compared to controls was significantly ameliorated by CANA (IR $31.7 \pm 3.2 \%$ vs. IR + CANA $51.9 \pm 2.5 \%, p<0.05)$. IR altered the expression of 17 genes. Ccl2, Ccl3, Ccl4, CxCr4, Fos, Icam1, Il10, Il1 $a$ and Il1b have been found to have the highest interaction. Compared to controls, IR significantly upregulated the mRNA expressions of $I l 1 a$ and $I l 6$, which were reduced by 1.5 - and 1.75-fold with CANA, respectively. CANA significantly prevented the upregulation of Cd40, downregulated NoxO1 gene expression, decreased ICAM-1 and nitrotyrosine, and increased PECAM-1 immunoreactivity. CANA alleviates endothelial dysfunction following IRI.

Keywords: ischemia/reperfusion; endothelial function; canagliflozin; sodium-glucose cotransporter2; diabetes mellitus

\section{Introduction}

Coronary artery bypass grafting (CABG) with autologous conduits remains one of the most frequently performed procedures to restore blood flow to ischemic myocardium. The harvest and perioperative storage of these vascular grafts results in endothelial dysfunction, which is further exacerbated by ischemia/reperfusion (IR) injury (IRI) upon implantation and restoration of blood flow. The reperfusion of previously ischemic tissue is accompanied by the rapid restoration of a physiologic $\mathrm{pH}$, calcium overload, ATP depletion, neutrophil influx, the generation of reactive oxygen species (ROS), the release of pro-inflammatory cytokines, and the enhanced expression of adhesion molecules, ultimately leading to vascular damage [1]. These events contribute to bypass graft failure, jeopardizing longterm clinical outcomes [2]. Therefore, there is an urgent need for the development of 
novel storage solutions to prolong vascular graft integrity and enhance long-term graft patency $[3,4]$.

Canagliflozin (CANA) is a member of a novel class of antidiabetic agents, selective sodium glucose-cotransporter (SGLT)-2 inhibitors, which have been approved for the treatment of patients with type-2 diabetes mellitus (T2DM) [5]. These medications reduce the kidneys' glucose reuptake, increasing urinary glucose excretion and thus lowering blood sugar levels [6]. The Canagliflozin Cardiovascular Assessment Study (CANVAS) Program [7] and CREDENCE trials [8] were designed to examine the potential cardiovascular effects of CANA. Interestingly, these trials have demonstrated reductions in the primary composite endpoint of cardiovascular death, nonfatal myocardial infarction, and nonfatal stroke compared to placebo and standard care in patients with T2DM [9]. Furthermore, two recent clinical trials (EMPEROR-Reduced [10] and DAPA-HF [11]) support the use of SGLT2 inhibitors for the treatment of patients with heart failure and a reduced ejection fraction, regardless of the presence or absence of diabetes. Additionally, it has been shown that short- or long-term administration of CANA attenuates myocardial IRI in diabetic and nondiabetic rats [12-14]. These findings support the hypothesis that CANA might also protect against vascular IRI, irrespective of diabetic status and raise the possibility of repurposing the SGLT-2 inhibitor as a novel cardioprotective intervention in high-risk nondiabetic patients with significant pre-existing cardiovascular disease. Indeed, we have recently shown that CANA has direct vasoactive properties in aortic rings from nondiabetic, healthy rats [14]. A recent in vitro study has shown that CANA conveys direct anti-inflammatory actions in lipopolysaccharide-stimulated human coronary artery endothelial cells [15]. Furthermore, Mancini et al. have demonstrated that in cultured endothelial cells CANA inhibited key proinflammatory cytokine secretion, such as IL- 6 and the chemokine monocyte chemoattractant protein (MCP)-1 (also known as CCL2) [16]. The increased expression of IL-6 recruits circulating leukocytes to the vascular wall by up-regulating chemokine production and adhesion molecule expression, contributing to endothelial dysfunction in part by increasing vascular superoxide and limiting nitric oxide (NO) bioavailability. Additionally, CANA has been shown to prevent diabetes-induced endothelial dysfunction in ApoE-deficient mice through its anti-inflammatory and antioxidative potential [17].

As the direct impact of CANA on IR-induced vascular damage has not been previously investigated, we hypothesized that physiological saline supplemented with CANA protects grafts from in vitro vascular IRI.

\section{Results}

2.1. Aortic Vasoreactivity Following Vascular IRI

\subsubsection{Effect of CANA on Endothelial Function after Vascular IRI}

Acetylcholine (ACh, $10^{-9}-10^{-4} \mathrm{M}$ ) induced concentration-dependent relaxation in aortic rings precontracted with phenylephrine (PE) in all experimental groups (Figure 1A). Reduced endothelium-dependent vasorelaxation in response to ACh in the IR group compared to controls was significantly improved by the preservation of aortic rings with CANA (Table 1, Figure 1A). Furthermore, decreased aortic sensitivity $\left(\mathrm{pD}_{2}\right.$-value) to ACh seen after IRI was significantly ameliorated by CANA (Table 1).

\subsubsection{Effects of CANA on Smooth Muscle Relaxation after Vascular IRI}

Sodium nitroprusside (SNP, $10^{-10}-10^{-5} \mathrm{M}$ ), an endothelium-independent vasodilator, evoked a concentration-dependent relaxation of PE precontracted aortic segments (Figure 1B). Although there was no difference in maximal relaxation to SNP, the concentration-response curve from the IR + CANA group was significantly left-shifted compared to that of the IR group (Table 1, Figure 1B). 
A

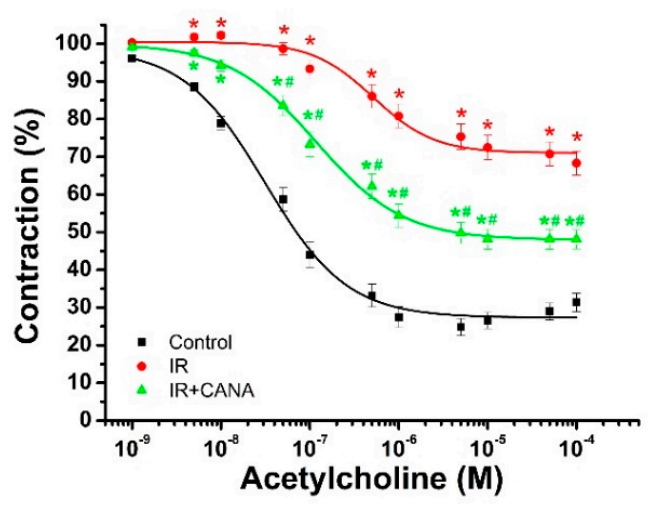

C

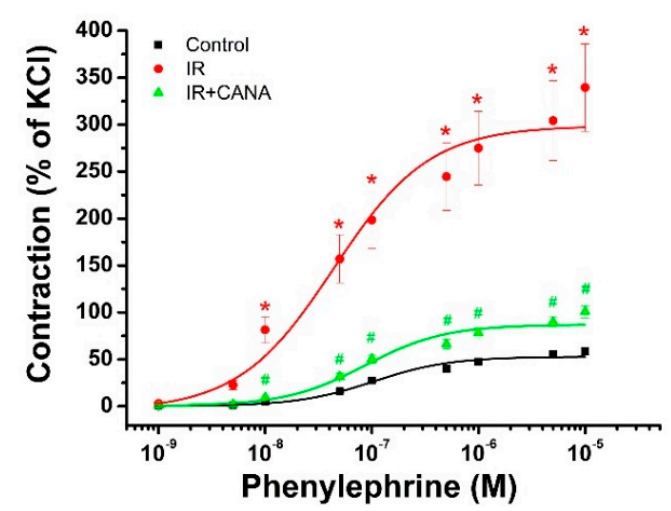

B

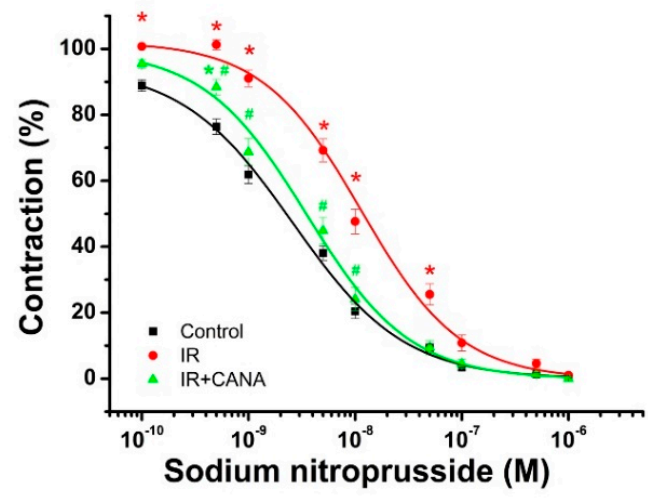

D

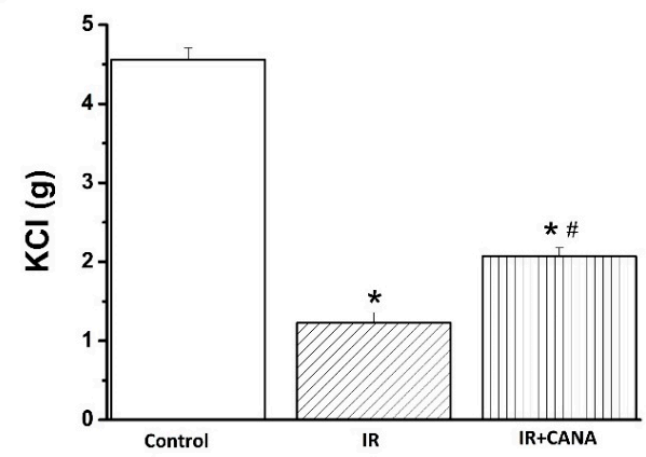

Figure 1. Effect of canagliflozin (CANA) on contractile and relaxation responses after vascular ischemia/reperfusion (IR) injury. (A) Acetylcholine-induced endothelium-dependent and (B) sodium nitroprusside-induced endotheliumindependent vasorelaxation, and contractile responses (C) to phenylephrine (percentage of the maximum contraction induced by potassium chloride $(\mathrm{KCl})$ ) and $(\mathbf{D})$ to high potassium-induced depolarization of isolated aortic rings. Results are represented as mean \pm SEM. ${ }^{*} p<0.05$ versus Control; ${ }^{\#} p<0.05$ versus IR. $\mathrm{n}=18-43$ aortic rings from $8-11$ rats.

Table 1. Quantitative analysis of vascular function after ischemia/reperfusion (IR) injury. Data are represented as mean \pm SEM. CANA indicates canagliflozin; PE, phenylephrine as the percentage of the maximum contraction induced by potassium chloride $(\mathrm{KCl})$; $\mathrm{ACh}$, acetylcholine; $\mathrm{SNP}$, sodium nitroprusside; $\mathrm{R}_{\max }$, maximal relaxation, and $\mathrm{pD}_{2}$, negative logarithm of the corresponding halfmaximal response $\left(\mathrm{EC}_{50}\right)$. ${ }^{*} p<0.05$ versus Control; ${ }^{*} p<0.05$ versus IR. $\mathrm{n}=18-43$ aortic rings from 8-11 rats.

\begin{tabular}{cccc}
\hline & Control & IR & IR + CANA \\
\hline $\mathrm{PE}(\%$ of $\mathrm{KCl})$ & $2.6 \pm 0.2$ & $2.5 \pm 0.1$ & $1.9 \pm 0.1^{*, \#}$ \\
$\mathrm{pD}$ to $\mathrm{PE}$ & $6.77 \pm 0.07$ & $7.20 \pm 0.14^{*}$ & $6.84 \pm 0.06^{\#}$ \\
$\mathrm{KCl}(\mathrm{g})$ & $4.6 \pm 0.2$ & $1.2 \pm 0.1^{*}$ & $2.1 \pm 0.1^{*}, \#$ \\
$\mathrm{R}_{\max }$ to $\mathrm{ACh}(\%)$ & $75.2 \pm 2.3$ & $31.7 \pm 3.2^{*}$ & $51.9 \pm 2.5^{*}, \#$ \\
$\mathrm{pD}$ to $\mathrm{ACh}$ & $7.35 \pm 0.08$ & $6.28 \pm 0.15^{*}$ & $6.86 \pm 0.09^{*}, \#$ \\
$\mathrm{R}_{\max }$ to SNP $(\%)$ & $99.4 \pm 0.2$ & $99.0 \pm 0.6$ & $100.0 \pm 0.0$ \\
$\mathrm{pD}$ to SNP & $8.65 \pm 0.06$ & $7.97 \pm 0.07^{*}$ & $8.49 \pm 0.09^{\#}$ \\
\hline
\end{tabular}

\subsubsection{Effects of CANA on Contractility after Vascular IRI}

Increased maximal PE-induced contractile response in the IR group compared to controls was significantly decreased via the preservation of aortic rings with CANAs (Table 1, Figure 1C). Increased sensitivity ( $\mathrm{pD}_{2}$-value) to PE in the IR rings compared to controls was significantly reduced by CANA (Table 1). Decreased maximal $80 \mathrm{mM}$ $\mathrm{K}^{+}$-induced contraction in the IR group compared to controls was significantly increased by CANA (Figure 1D). 


\subsection{Effects of CANA on Aortic Gene Expression Following Vascular IRI}

To determine the effects of CANA on IRI-induced vascular changes, the expression levels of 88 genes involved in oxidative stress, apoptosis, and inflammation were simultaneously surveyed using $\mathrm{RT}^{2}$ polymerase chain reaction (PCR) Profiler. Among them, the expression of 17 genes was significantly altered in the IR group compared to controls (16 genes were upregulated: Ccl12, Ccl2, Ccl3, Ccl4, Cd40, Cxcr4, Edn1, Fos1, Hspa1a, Icam1, Il10, Il1a, Il1b, Il6, Sele, Tnf and 1 gene was downregulated: Ccl5, Table 2, first column). Compared to the controls, the upregulated mRNA expression of Il1 $a$ and Il6 in the IR rings was reduced 1.5- and 1.75-fold with CANA, respectively. Furthermore, CANA prevented the upregulation of $C d 40$ and significantly downregulated NoxO1 gene expression compared to controls (Table 2, second column). Figure 2 shows clustergram analysis and heat map graphs of gene expression data.

\subsection{Aortic Gene Expression Explored by Machine Learning Algorithms}

A computational analysis using Crossboruta was performed on the gene expression profiles. Figure 3A displays the network of genes predictive for inter-group classification. The right portion of the network graph, observes that the node "study arm" (Control/IR/IR + CANA) is connected to a cluster of positively intercorrelated genes. The periphery shows Ccl3, CxCr4, Ccl4, Il1b, Icam1, Il10, Ccl2, Il1a and Fos. The cluster's centroid contains the Il6 and Tnf, suggesting that these two might play a central role in IRI's pathophysiology. Figure 3B depicts the random-forest based gene selection; the variables confirmed as predictive in the group classification are Fos, Gpx1 and Hspa1a in the IR + CANA rings and Cd40, Icam1, Il10, Il1b, Il6, Il7 and Nox4 in the IR group. Il1a, Il6, $C d 40$ and Icam 1 were not predictive for the IR + CANA group but were predictive for the IR aortic rings (Figure 3B).

2.4. Effects of CANA on Aortic Intercellular Adhesion Molecule (ICAM)-1, Platelet Endothelial Cell Adhesion Molecule (PECAM)-1, Nitrotyrosine, and Caspase-3 Immunoreactivity after Vascular IRI

Immunohistochemical analysis showed that increased ICAM-1 immunoreactivity in the IR group compared to controls was significantly decreased by preservation of aortic rings with CANA (Figure 4A). Furthermore, decreased PECAM-1 positivity confined to the endothelial layer in the IR rings compared to controls was significantly increased after CANA treatment (Figure 4B).

Additionally, immunohistochemical data for nitrotyrosine showed lower brown staining in the aortic rings from IR + CANA compared to both control and IR groups (Figure 5A), whereas caspase- 3 immunoreactivity was not different among the groups (Figure $5 \mathrm{~B}$ ). 


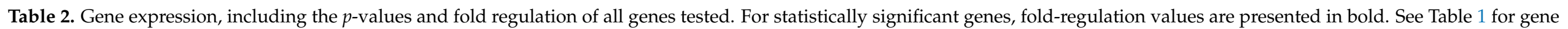

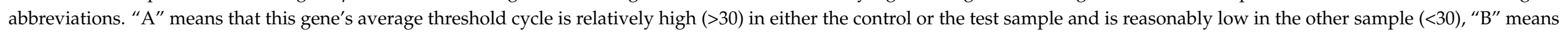

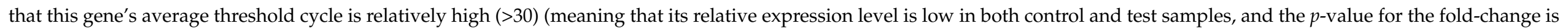

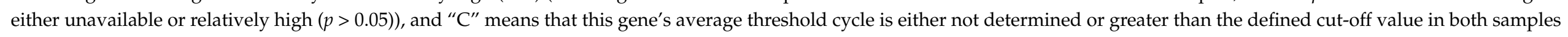
(meaning that its expression was undetected, making this fold-change result erroneous and uninterpretable). IR indicates ischemia/reperfusion and CANA canagliflozin.

\begin{tabular}{|c|c|c|c|c|c|c|c|c|c|c|c|}
\hline \multicolumn{4}{|c|}{$\begin{array}{l}\text { IR vs. } \\
\text { Control }\end{array}$} & \multicolumn{4}{|c|}{$\begin{array}{c}\text { IR + CANA vs. } \\
\text { Control }\end{array}$} & \multicolumn{4}{|c|}{$\begin{array}{c}\text { IR + CANA vs. } \\
\text { IR }\end{array}$} \\
\hline Symbol & $p$-Value & Regulation & Comments & Symbol & $p$-Value & Regulation & Comments & Symbol & $p$-Value & Regulation & Comments \\
\hline Aifm1 & 0.527 & 1.06 & & Aifm1 & 0.277 & 1.09 & & Aifm1 & 0.764 & 1.03 & \\
\hline Apaf1 & 0.716 & 1.03 & & Apaf1 & 0.361 & 1.06 & & Apaf1 & 0.67 & 1.04 & \\
\hline Bad & 0.059 & -1.17 & & Bad & 0.894 & -1.01 & & Bad & 0.05 & 1.16 & \\
\hline Bak1 & 0.374 & -1.1 & & Bak1 & 0.532 & -1.07 & & Bak1 & 0.545 & 1.03 & \\
\hline Bax & 0.023 & 1.1 & & Bax & 0.168 & 1.06 & & Bax & 0.259 & -1.04 & \\
\hline Bcl2 & 0.123 & 1.06 & & Bcl2 & 0.791 & -1.00 & & $\mathrm{Bcl} 2$ & 0.071 & -1.06 & \\
\hline Bcl2L1 & 0.321 & 1.09 & & Bcl2L1 & 0.453 & 1.08 & & $B c l 2 L 1$ & 0.919 & -1.01 & \\
\hline Bid & 0.068 & 1.83 & & Bid & 0.252 & 1.41 & & Bid & 0.041 & -1.29 & \\
\hline Casp1 & 0.018 & -1.28 & & Casp1 & 0.061 & -1.27 & & Casp1 & 0.945 & 1.01 & \\
\hline Casp12 & 0.055 & 1.18 & & Casp12 & 0.229 & 1.11 & & Casp12 & 0.241 & -1.07 & \\
\hline Casp3 & 0.256 & 1.1 & & Casp3 & 0.247 & 1.11 & & Casp3 & 0.91 & 1.01 & \\
\hline Casp4 & 0.146 & 1.18 & & Casp4 & 0.156 & 1.19 & & Casp4 & 0.814 & 1.01 & \\
\hline Casp6 & 0.276 & 1.17 & & Casp6 & 0.863 & -1.03 & & Casp6 & 0.191 & -1.21 & \\
\hline Casp7 & 0.607 & 1.06 & & Casp7 & 0.026 & 1.26 & & Casp7 & 0.128 & 1.19 & \\
\hline Casp8 & 0.461 & 1.08 & & Casp8 & 0.059 & 1.20 & & Casp8 & 0.266 & 1.1 & \\
\hline Ccl11 & 0.171 & 1.64 & & Col11 & 0.841 & 1.07 & & Col11 & 0.246 & -1.52 & \\
\hline Ccl12 & 0 & 8.55 & & Col12 & 0 & 10.09 & & Ccl12 & 0.658 & 1.18 & \\
\hline $\mathrm{Ccl} 2$ & 0 & 24.21 & & $\mathrm{Ccl} 2$ & 0 & 21.75 & & $\mathrm{Ccl} 2$ & 0.53 & -1.11 & \\
\hline Ccl20 & 0.787 & -1.01 & C & Ccl20 & 0.137 & -1.08 & C & Ccl20 & 0.089 & -1.06 & C \\
\hline $\mathrm{Ccl} 3$ & 0.003 & 71.33 & & $\mathrm{Ccl} 3$ & 0.003 & 75.18 & & $\mathrm{Ccl} 3$ & 0.73 & 1.05 & \\
\hline Ccl4 & 0 & 34.85 & & Col4 & 0 & 36.45 & & Col4 & 0.806 & 1.05 & \\
\hline Ccl5 & 0.011 & -2.81 & & Ccl5 & 0.012 & -2.82 & & Ccl5 & 0.985 & -1 & \\
\hline Cor 1 & 0.153 & -4.21 & & Cor1 & 0.028 & -1.65 & & Cor1 & 0.326 & 2.55 & \\
\hline Ccr 2 & 0.461 & -1.18 & & Ccr 2 & 0.776 & -1.05 & & Cor 2 & 0.556 & 1.12 & \\
\hline Ccs & 0.113 & -1.22 & & Ccs & 0.163 & -1.1 & & Cos & 0.349 & 1.11 & \\
\hline$C d 40$ & 0.004 & 2.13 & & $\mathrm{Cd} d 40$ & 0.04 & 1.6 & & $\mathrm{Cd} d 40$ & 0.206 & -1.34 & \\
\hline cd40lg & 0.281 & -1.56 & B & cd40lg & 0.882 & -1.07 & B & cd40lg & 0.428 & 1.46 & B \\
\hline
\end{tabular}


Table 2. Cont.

\begin{tabular}{|c|c|c|c|c|c|c|c|c|c|c|c|}
\hline \multicolumn{4}{|c|}{$\begin{array}{l}\text { IR vs. } \\
\text { Control }\end{array}$} & \multicolumn{4}{|c|}{$\begin{array}{c}\text { IR + CANA vs. } \\
\text { Control }\end{array}$} & \multicolumn{4}{|c|}{$\begin{array}{c}\text { IR + CANA vs. } \\
\text { IR }\end{array}$} \\
\hline Symbol & $p$-Value & Regulation & Comments & Symbol & $p$-Value & Regulation & Comments & Symbol & $p$-Value & Regulation & Comments \\
\hline Cflar & 0.894 & 1.01 & & Cflar & 0.675 & 1.02 & & Cflar & 0.885 & 1.01 & \\
\hline $\mathrm{CxCr} 4$ & 0 & 4.47 & & $\mathrm{CxCr} 4$ & 0 & 3.37 & & $\mathrm{CxCr} 4$ & 0.144 & -1.32 & \\
\hline$C y b a$ & 0.092 & 1.07 & & Cyba & 0.281 & 1.1 & & $C y b a$ & 0.706 & 1.03 & \\
\hline cycs & 0.825 & 1.02 & & cycs & 0.972 & 1 & & cycs & 0.807 & -1.01 & \\
\hline Duox1 & 0.998 & -1 & B & Duox1 & 0.666 & -1.1 & B & Duox1 & 0.798 & -1.09 & B \\
\hline$E d n 1$ & 0.002 & 2.44 & & $E d n 1$ & 0.017 & 2.06 & & $E d n 1$ & 0.556 & -1.19 & \\
\hline$E p x$ & 0.746 & 1.06 & & $E p x$ & 0.587 & 1.1 & & Epx & 0.806 & 1.04 & \\
\hline Fadd & 0.954 & -1 & & Fadd & 0.955 & -1 & & Fadd & 0.978 & 1 & \\
\hline Fas & 0.973 & -1.01 & B & Fas & 0.081 & -1.87 & B & Fas & 0.06 & -1.85 & B \\
\hline Faslg & 0.926 & 1.02 & & Faslg & 0.932 & -1.02 & & Faslg & 0.877 & -1.05 & \\
\hline Flt1 & 0.143 & -1.22 & & Flt1 & 0.242 & -1.09 & & Flt1 & 0.352 & 1.12 & \\
\hline Fos & 0 & 51.6 & & Fos & 0 & 54.88 & & Fos & 0.348 & 1.06 & \\
\hline Gpx1 & 0.738 & 1.02 & & Gpx1 & 0.065 & 1.11 & & Gpx1 & 0.054 & 1.09 & \\
\hline Gpx2 & 0.279 & 2.01 & B & Gpx2 & 0.144 & 2.12 & B & Gpx2 & 0.922 & 1.06 & B \\
\hline Gpx3 & 0.696 & 1.05 & & Gpx3 & 0.909 & 1.01 & & Gpx3 & 0.678 & -1.04 & \\
\hline Gpx6 & 0.787 & -1.01 & $\mathrm{C}$ & Gpx6 & 0.137 & -1.08 & $\mathrm{C}$ & Gpx6 & 0.089 & -1.06 & $\mathrm{C}$ \\
\hline Gpx7 & 0.647 & 1.03 & & $G p x 7$ & 0.286 & 1.08 & & Gpx7 & 0.453 & 1.05 & \\
\hline Gstk1 & 0.305 & 1.11 & & Gstk1 & 0.453 & 1.07 & & Gstk1 & 0.655 & -1.04 & \\
\hline Hspa1a & 0 & 4.63 & A & Hspa1a & 0 & 5.65 & A & Hspa1a & 0.376 & 1.22 & \\
\hline Icam1 & 0 & 4.34 & & Icam1 & 0 & 3.66 & & Icam1 & 0.233 & -1.19 & \\
\hline Il10 & 0 & 35.06 & A & Il10 & 0 & 38.69 & A & Il10 & 0.63 & -1.1 & \\
\hline Il18 & 0.817 & 1.03 & & Il18 & 0.316 & -1.16 & & Il18 & 0.306 & -1.2 & \\
\hline Il1a & 0 & 210.71 & A & Illa & 0 & 138.48 & A & Illa & 0.193 & -1.52 & \\
\hline$I l 1 b$ & 0 & 28.95 & & $I l 1 b$ & 0 & 24.13 & & $I l 1 b$ & 0.386 & -1.2 & \\
\hline Il6 & 0 & 95.21 & & Il6 & 0 & 53.87 & & Il6 & 0.086 & -1.77 & \\
\hline Il7 & 0.238 & -1.38 & & Il7 & 0.693 & 1.08 & & Il7 & 0.099 & 1.48 & \\
\hline Il9 & 0.381 & -1.22 & B & $I l 9$ & 0.659 & -1.12 & B & Il9 & 0.591 & 1.09 & B \\
\hline $\operatorname{Itg} b 2$ & 0.028 & -1.44 & & $\operatorname{Itg} b 2$ & 0.015 & -1.55 & & $\operatorname{Itg} b 2$ & 0.668 & -1.08 & \\
\hline Jun & 0.005 & 1.34 & & Jun & 0.027 & 1.31 & & Jun & 0.813 & -1.02 & \\
\hline Ncf1 & 0.827 & 1.03 & & Ncf1 & 0.136 & -1.12 & & Ncf1 & 0.247 & -1.16 & \\
\hline$N f k b 1$ & 0.046 & 1.11 & & $N f k b 1$ & 0.074 & 1.11 & & $N f k b 1$ & 0.96 & -1 & \\
\hline
\end{tabular}


Table 2. Cont.

\begin{tabular}{|c|c|c|c|c|c|c|c|c|c|c|c|}
\hline \multicolumn{4}{|c|}{$\begin{array}{l}\text { IR vs. } \\
\text { Control }\end{array}$} & \multicolumn{4}{|c|}{$\begin{array}{c}\text { IR + CANA vs. } \\
\text { Control }\end{array}$} & \multicolumn{4}{|c|}{$\begin{array}{c}\text { IR + CANA vs. } \\
\text { IR }\end{array}$} \\
\hline Symbol & $p$-Value & Regulation & Comments & Symbol & $p$-Value & Regulation & Comments & Symbol & $p$-Value & Regulation & Comments \\
\hline Nos2 & 0.891 & -1.08 & $\mathrm{~B}$ & Nos2 & 0.686 & 1.29 & B & Nos2 & 0.567 & 1.39 & B \\
\hline Nox4 & 0.023 & 1.35 & & Nox4 & 0.372 & 1.11 & & Nox 4 & 0.14 & -1.21 & \\
\hline Noxo1 & 0.127 & -1.9 & $\mathrm{~B}$ & Noxo1 & 0.036 & -2.27 & B & Noxo1 & 0.674 & -1.2 & $\mathrm{~B}$ \\
\hline $\operatorname{Prdx1}$ & 0.239 & 1.12 & & $\operatorname{Prdx1}$ & 0.376 & 1.09 & & $\operatorname{Prdx1}$ & 0.178 & -1.03 & \\
\hline $\operatorname{Prdx} 2$ & 0.01 & 1.23 & & $\operatorname{Prd} 22$ & 0.026 & 1.21 & & $\operatorname{Prd} x 2$ & 0.593 & -1.02 & \\
\hline $\operatorname{Prdx3}$ & 0.099 & 1.19 & & $\operatorname{Prdx} 3$ & 0.088 & 1.21 & & $\operatorname{Prdx} 3$ & 0.841 & 1.01 & \\
\hline $\operatorname{Prdx} 4$ & 0.179 & 1.09 & & $\operatorname{Prdx} 4$ & 0.027 & 1.14 & & $\operatorname{Prdx} 4$ & 0.49 & 1.05 & \\
\hline Sele & 0 & 8.3 & A & Sele & 0 & 9.81 & $\mathrm{~A}$ & Sele & 0.644 & 1.18 & \\
\hline Slc5a1 & 0.241 & -1.23 & B & Slc5a1 & 0.847 & -1.06 & $\mathrm{~B}$ & Slc5a1 & 0.516 & 1.16 & B \\
\hline Sod1 & 0.352 & -1.09 & & Sod1 & 0.948 & -1.01 & & Sod1 & 0.234 & 1.09 & \\
\hline Sod2 & 0.005 & 1.32 & & Sod2 & 0.001 & 1.33 & & Sod2 & 0.991 & 1 & \\
\hline Sod3 & 0 & 1.24 & & Sod3 & 0.002 & 1.36 & & Sod3 & 0.217 & 1.1 & \\
\hline$T g f b 1$ & 0.129 & 1.11 & & $T g f b 1$ & 0.176 & 1.09 & & $T g f b 1$ & 0.764 & -1.02 & \\
\hline Tlr1 & 0.082 & -1.49 & & Tlr1 & 0.183 & -1.27 & & Tlr1 & 0.468 & 1.18 & \\
\hline Tlr4 & 0.83 & 1.03 & & Tlr4 & 0.284 & 1.19 & & Tlr4 & 0.267 & 1.16 & \\
\hline Tnfrsf $12 a$ & 0.947 & 1.01 & & Tnfrsf12a & 0.609 & -1.1 & & Tnfrsf12a & 0.462 & -1.12 & \\
\hline Tollip & 0.06 & 1.1 & & Tollip & 0.027 & 1.2 & & Tollip & 0.204 & 1.1 & \\
\hline Tp53 & 0.051 & 3.7 & B & Tp53 & 0.076 & 4.79 & B & Tp53 & 0.762 & 1.3 & B \\
\hline Txn1 & 0.202 & 1.05 & & Txn1 & 0.386 & 1.03 & & Txn1 & 0.437 & -1.02 & \\
\hline Txnrd1 & 0 & 1.28 & & Txnrd1 & 0 & 1.34 & & Txnrd1 & 0.325 & 1.05 & \\
\hline Txnrd2 & 0.428 & 1.04 & & Txnrd2 & 0.773 & 1.02 & & Txnrd2 & 0.772 & -1.02 & \\
\hline Vcam1 & 0.011 & 1.73 & & Vcam1 & 0.024 & 1.75 & & Vcam1 & 0.934 & 1.01 & \\
\hline$V e g f c$ & 0.156 & 1.24 & & $V e g f c$ & 0.154 & 1.26 & & $V e g f c$ & 0.87 & 1.02 & \\
\hline Xiap & 0.381 & 1.1 & & Xiap & 0.14 & 1.21 & & Xiap & 0.116 & 1.09 & \\
\hline
\end{tabular}


A

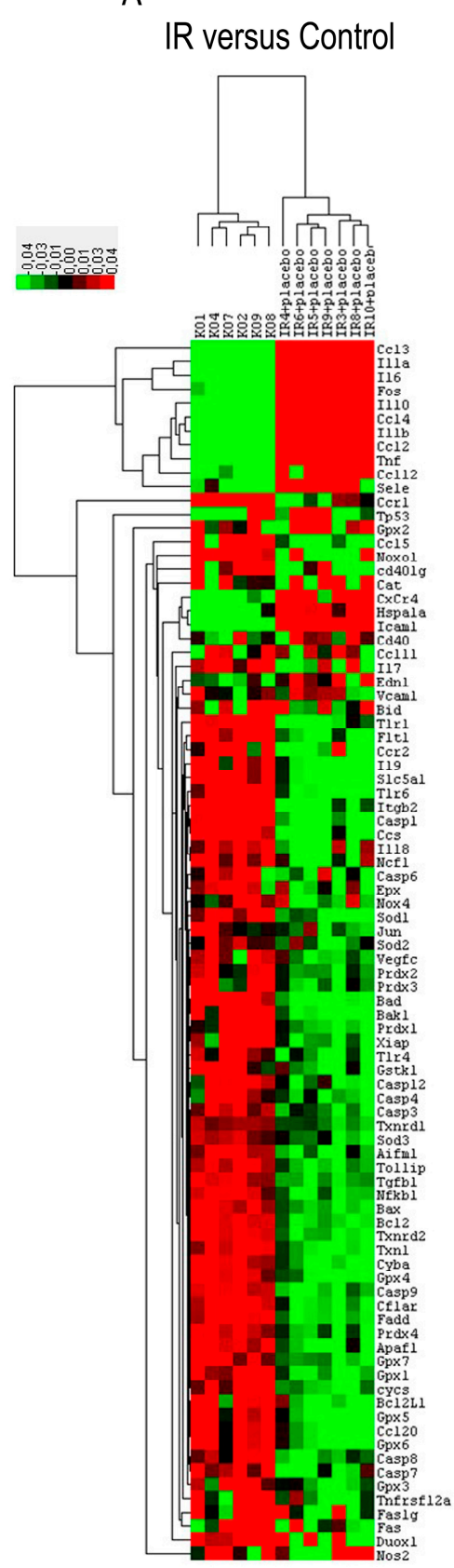

B

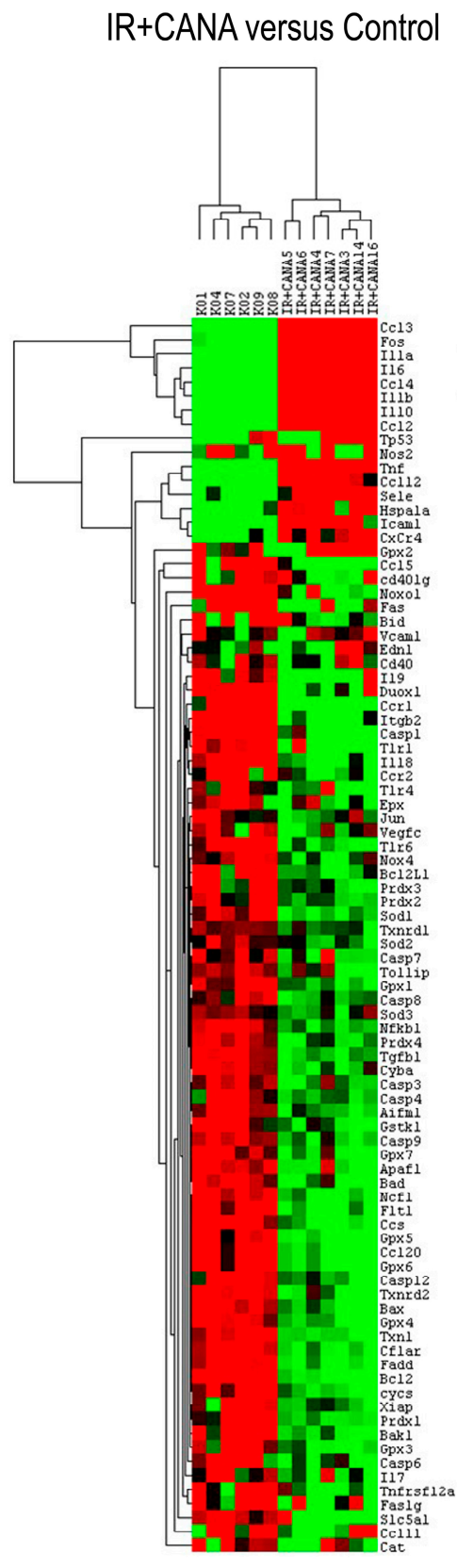

C

IR+CANA versus IR

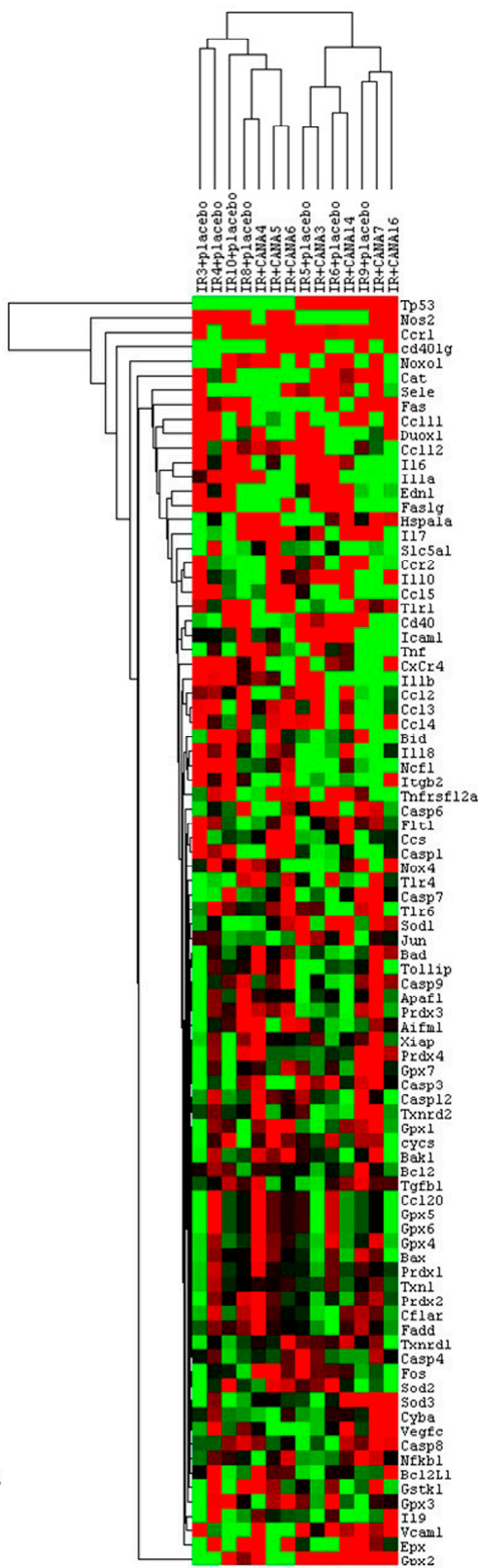

Figure 2. Changes in gene expression caused by vascular ischemia/reperfusion (IR) injury and the effect of canagliflozin (CANA). The expression of 88 genes involved in inflammation, apoptosis, and oxidative stress has been profiled. Clustergrams create a heat map with dendograms to indicate which genes are coregulated. Degrees of red and green indicate relatively high and low expression of the corresponding gene, respectively, and black squares denote genes equally expressed. (A) IR vs. Control, (B) IR + CANA vs. Control, and (C) IR + CANA vs. IR groups. The $x$-axis indicates number of rats ("KO" corresponds to the Control group, including six rats (KO1, $\mathrm{KO} 2, \mathrm{KO} 4, \mathrm{KO}$, $\mathrm{KO}$, $\mathrm{KO} 9$ ), "IR + placebo" corresponds to the IR group, including seven rats (IR3 + placebo, IR4 + placebo, IR5 + placebo, IR6 + placebo, IR8 + placebo, IR9 + placebo, IR10 + placebo), and "IR + CANA" corresponds to the IR + canagliflozin group, including seven rats $(\mathrm{IR}+\mathrm{CANA3}, \mathrm{IR}+\mathrm{CANA4}, \mathrm{IR}+\mathrm{CANA} 5, \mathrm{IR}+\mathrm{CANA6}, \mathrm{IR}+\mathrm{CANA7}, \mathrm{IR}+\mathrm{CANA14}, \mathrm{IR}+\mathrm{CANA16}))$ and the $y$-axis indicates the genes. $n=6-7$ rats/group. See Table 1 for genes' abbreviations. 


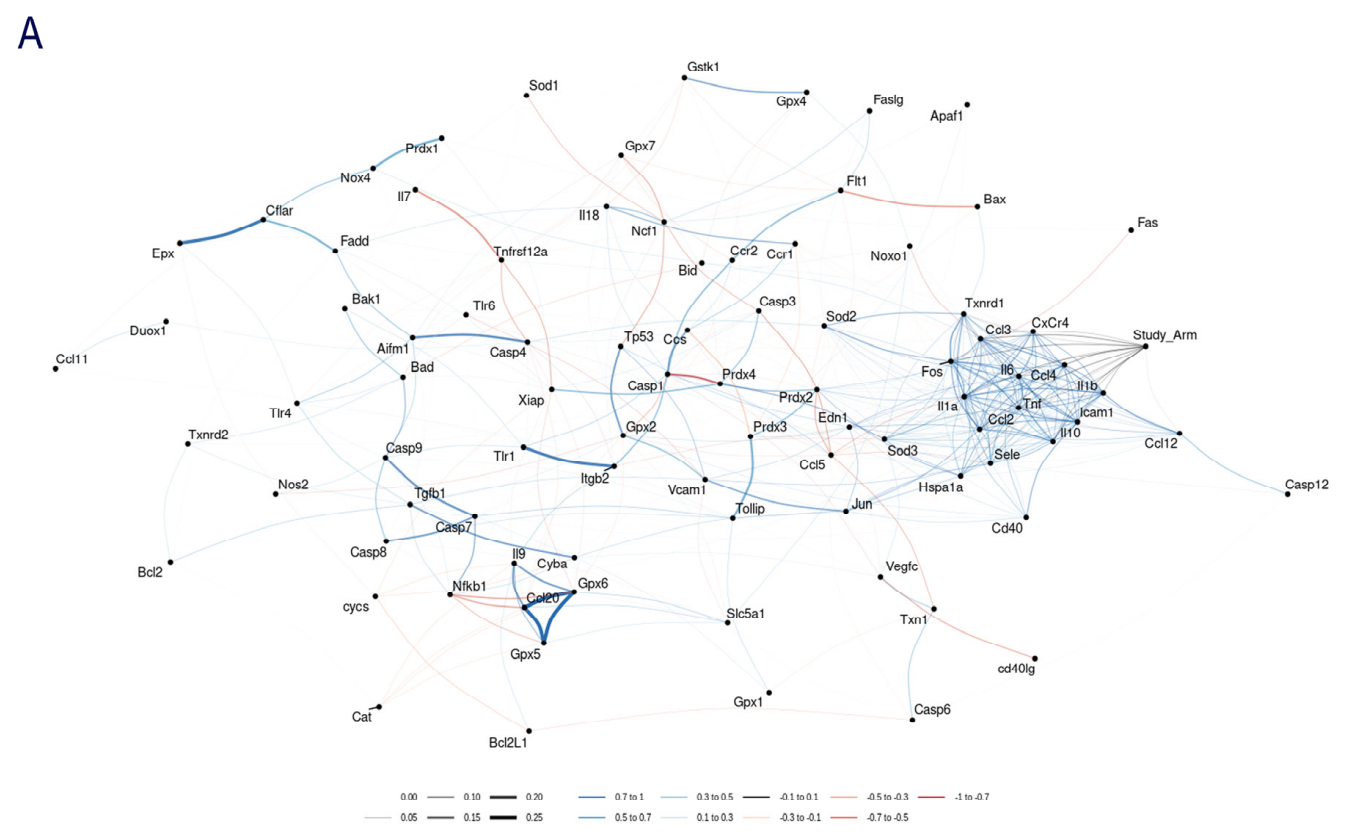

B

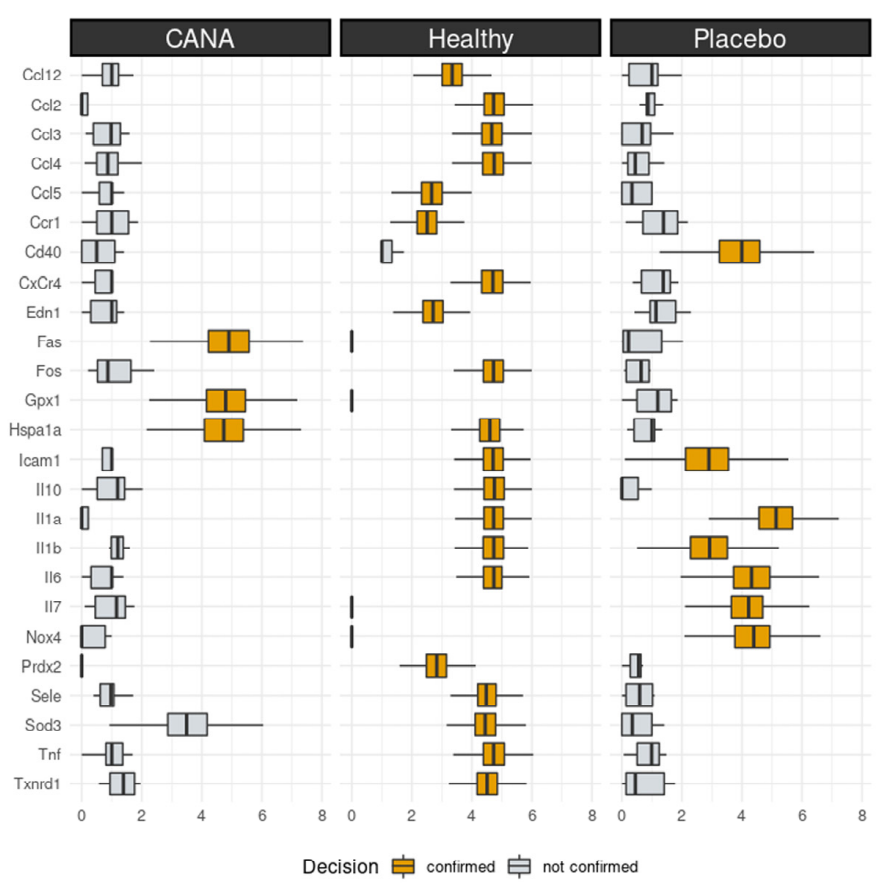

Figure 3. Machine-learning analysis: (A) Gene correlation network: a node represents each investigated gene. The closeness between nodes and the connection width are proportional to the random-forest variable importance. The colors indicate the Spearman's coefficients: blue or red lines are associated with a positive or negative correlation, respectively. The grey connections are random-forest patterns without a significant Spearman coefficient. "Study arm" is the group variable: Control/IR/IR + CANA. This node is connected (right side of the network), with a cluster of genes, including Txnrd1, Ccl3, CxCr4, Il6, Ccl4, Il1b, Tnf, Ccl2, Il10, IL1a, Fos, Sod3, Hspa1a, Cd40, Ccl12 and Icam1. These genes are in a significant positive Spearman correlation with each other. In contrast, the other tested genes do not show a cluster pattern. (B) Genes predicting the experimental group (Control, IR, or IR + CANA). The genes identified with the yellow horizontal box plots respond to the question: "is this IR + CANA or not?", "is this Control or not?", "is this IR or not?". The Y-axis depicts genes (abbreviations are defined in Table 1) and the horizontal axis indicates the predictive power of a gene for the group identification, as calculated by the random forest model. IR indicates ischemia/reperfusion, CANA canagliflozin. 
A
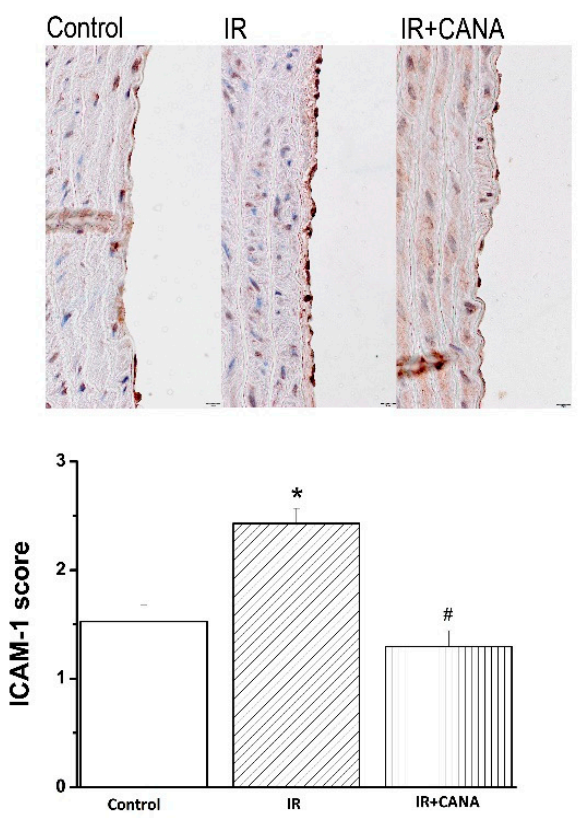
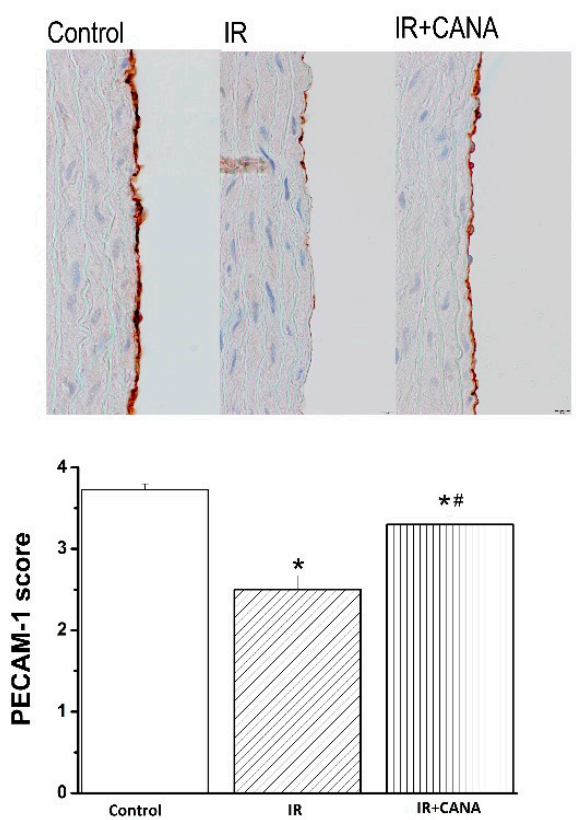

Figure 4. Effect of canagliflozin (CANA) on aortic intercellular adhesion molecule (ICAM)-1 and platelet endothelial cell adhesion molecule (PECAM)-1/CD31 expression after vascular ischemia/reperfusion (IR) injury. Semiquantitative scoring of (A) ICAM-1 and (B) PECAM-1 immunohistochemical staining with representative micrographs $(\times 400$, scale: $10 \mu \mathrm{m})$. Results are represented as mean \pm SEM. ${ }^{*} p<0.05$ versus Control; ${ }^{\#} p<0.05$ versus IR. $\mathrm{n}=28-40$ aortic rings from $7-10$ rats.

A
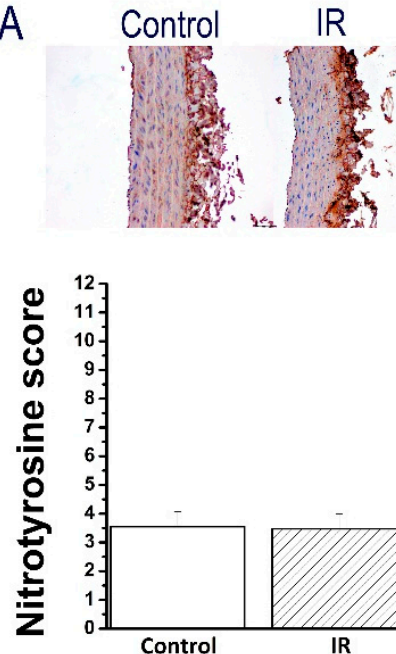
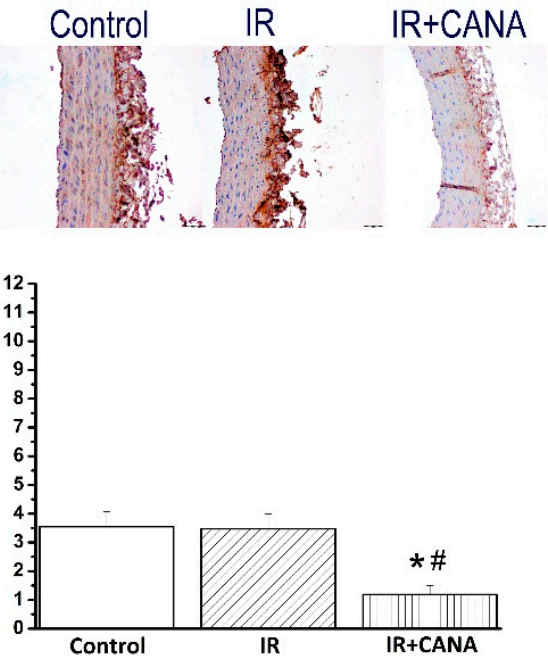

B
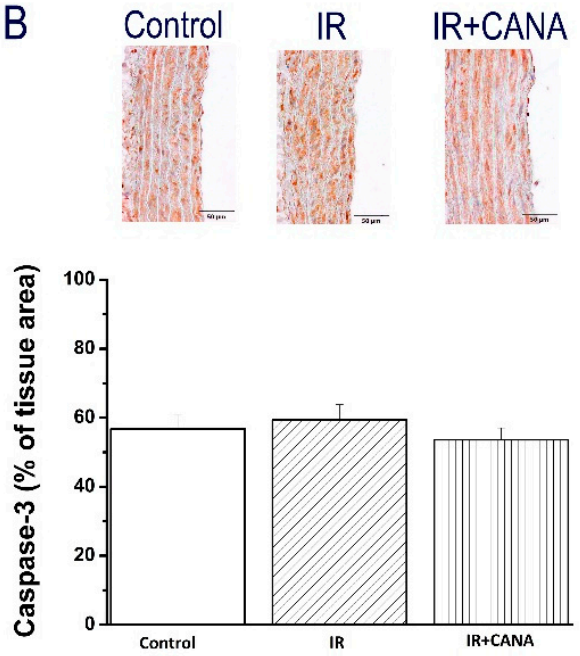

Figure 5. Effect of canagliflozin (CANA) on aortic nitrotyrosine and caspase-3 expression after vascular ischemia/reperfusion (IR) injury. (A) Semiquantitative scoring of nitrotyrosine and (B) quantitative analysis of caspase-3 immunohistochemical staining with representative micrographs (scale: $50 \mu \mathrm{m}$ ). Results are represented as mean $\pm \mathrm{SEM}$. ${ }^{*} p<0.05$ versus Control; ${ }^{\#} p<0.05$ versus IR. $\mathrm{n}=32-44$ aortic rings from $8-11$ rats.

\section{Discussion}

In the present work, we hypothesized that adding CANA, an SGLT2 inhibitor developed for the treatment of hyperglycemia in T2DM, to storage solution (physiological saline), protects the vascular grafts of nondiabetic rats against IRI. To our knowledge, this is the first study to suggest that the preservation of aortic rings with CANA alleviates vascular dysfunction following in vitro IRI. CANA could exert protective effects by lowering inflammatory response through ICAM-1, PECAM-1 and genes for Il1a, Il6a, NoxO1 and 
Cd40, without leukocyte engagement. A graphic summary of our main findings is provided in Figure 6.

CABG is a surgical procedure performed to restore blood flow to areas of the ischemic myocardium supplied by a coronary artery with stenosis. An autologous vessel is used as a graft in most cases. During harvesting these vessels, vascular damage occurs that has a negative impact on future graft patency, and hence on clinical outcomes following CABG. In the present study, an isolated tissue bath system was used to assess the effects of IRI on vascular functional changes. We have confirmed that IRI decreased both endothelium-dependent vasorelaxation and sensitivity to exogenous $\mathrm{ACh}$, impaired smooth muscle relaxation to SNP (an endothelium-independent vasodilator), impaired contraction produced by high potassium chloride $(\mathrm{KCl})$ concentrations and by an $\alpha$-adrenergic receptor agonist PE in aortic rings originating from healthy, nondiabetic rats. Evidence implicates that inflammation, oxidative stress, and apoptosis play a critical role in the vascular response to IRI [18]. We profiled the aortic expression 88 genes involved in the above-mentioned pathways and described that IRI altered the expression of 17 genes $(\mathrm{Ccl12}, \mathrm{Ccl} 2, \mathrm{Ccl} 3, \mathrm{Ccl} 4, \mathrm{Cd} 40, \mathrm{Cxcr} 4$, Edn1, Fos1, Hspa1a, Icam1, Il10, Il1a, Il1b, Il6, Sele and Tnf were upregulated and Ccl5 was downregulated) compared to controls. The PCR array data was further analyzed with random-forest-based algorithms to gain novel insights. Among the tested 88 genes, Ccl2, Ccl3, Ccl4, CxCr4, Fos, Icam1, Il10, Illa and Il1b have been found to have higher gene-gene interaction than the others, indicating the biological significance of these genes. Two genes, Il6 and Tnf, were identified to have a central role in IRI's pathophysiology in our setup. These findings may indicate a relationship between these genes and the cause of vascular dysfunction in aortic rings submitted to IRI from nondiabetic rats. Finally, we performed immunohistochemistry to determine if IRI was associated with cellular changes in the aorta. Our results showed that IRI significantly altered the protein expression levels of major intercellular adhesion molecules such as ICAM-1 and PECAM-1, which play important roles in inflammatory processes of the vasculature.

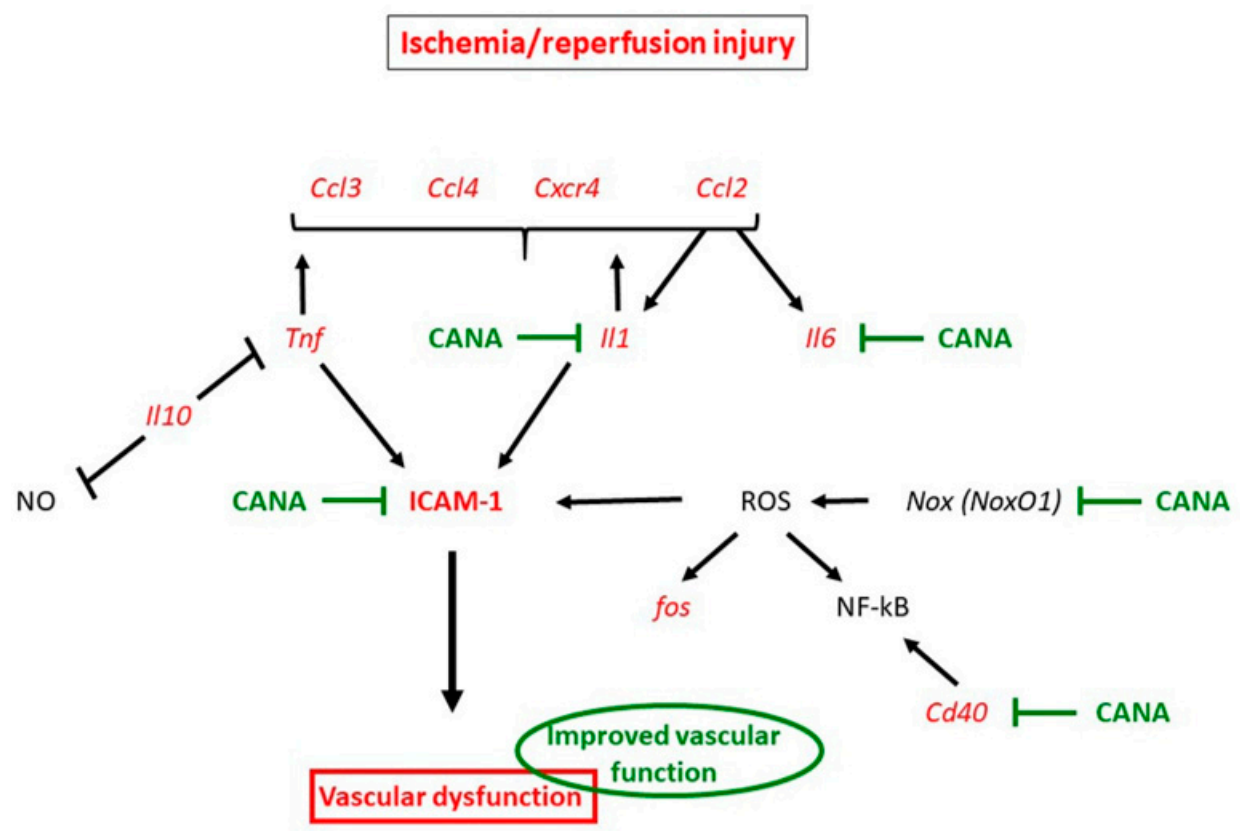

Figure 6. Simplified diagram illustrating the protective effect of canagliflozin (CANA) after vascular ischemia/reperfusion injury (IRI). IRI significantly increased the mRNA expression of Tnf and Il1, which may increase the expression of Ccl3, Ccl4, Cxcr4, Ccl2 and ICAM-1. Additionally, IRI increased fos and Ccl2 expression and may upregulate Il1 and Il6, all leading to vascular dysfunction. CANA reduced ICAM-1 expression possibly via preventing the upregulation of the key proinflammatory mediators Il1, Il6 and $C d 40$ and by down-regulating NoxO1, thereby alleviating endothelial dysfunction. Effects of IRI are indicated by red colors and CANA is indicated by green colors. See Table 1 for gene abbreviations. 


\subsection{Mechanisms Underlying Protective Effects of CANA against IRI in Vasculature}

In the clinical setting, an important issue is the development of novel preservation solutions/methods to protect endothelial cell function against IRI. The SGLT2 inhibitor CANA, a novel oral antidiabetic agent, has been shown to attenuate IRI in the heart [12,14]. We investigated graft preservation in physiological saline enriched with CANA in an experimental model of vascular dysfunction induced by IRI. The principal novelty is that incubation of aortic rings originating from nondiabetic rats protected against endothelial dysfunction following IRI ex vivo (evidenced by improved endothelium-dependent vasorelaxation and increased aortic ring sensitivity to $\mathrm{ACh}$ ). It has been suggested that the direct inhibition of SGLT-2 in the vascular wall contributes to improvement in endothelial function [19]. In the endothelium, muscarinic ACh receptors trigger NO production via endothelial NO synthase (eNOS), which plays a crucial role in regulating vascular function, local blood flow, leukocyte-endothelial cell interactions, platelet aggregation, and adhesion [20]. Reperfusion subsequent to ischemia leads to an extensive inflammatory response characterized by the enhanced expression of adhesion molecules. PECAM-1/CD31, a multifunctional cell adhesion molecule, has been shown to maintain eNOS activity and NO bioavailability [21] and to regulate the extravasation of leukocytes during inflammatory processes [22]. In line with these observations, we have shown that CANA significantly increased the expression of CD31 in IR aortic rings. Additionally, inflammatory molecule ICAM-1 expression can be upregulated by many cytokines and agonists (such as IL-1, TNF and interferon (IFN)- $\gamma$ ) [23], as well as by cytokine-independent stimuli (such as free radicals and hypoxia) [24]. In the present study, we have found that mRNA expression of Il1, Tnf and Icam1 was significantly upregulated by IRI, and CANA lowered ICAM-1 immunoreactivity and reduced the gene expression of pro-inflammatory cytokines Illa and Il6 by 1.5 - and 1.75 -fold, respectively. A recent study demonstrated that 8-week CANA treatment $(30 \mathrm{mg} / \mathrm{kg} /$ day $)$ ameliorated endothelium-dependent vasodilation in diabetic atherosclerotic mouse model [17]. The expression of adhesion molecule ICAM-1 was significantly reduced by CANA in $\mathrm{ApoE}^{-/-}$mice, indicating that CANA attenuated vascular inflammation [17]. In our study, we demonstrated that down-expression of ICAM-1 by CANA in aortic rings submitted to in vitro IRI (i.e., in the absence of leucocyte binding) was associated with less endothelial dysfunction. Consistent with our results, Clark et al. have shown that elevated ICAM- 1 expression in cultured endothelial cells can cause vascular leakiness, cytoskeletal reorganization, and junctional protein alterations without the contribution of leukocytes [25]. Furthermore, the machine-learning algorithms showed that Il1a, Il6, Cd40 and Icam 1 were not predictive for the IR + CANA group, but were predictive for the IR aortic rings, suggesting that CANA modifies the expression of the above-mentioned genes. In line with our observation, Mancini et al. have demonstrated that CANA directly inhibits the secretion of proinflammatory cytokine IL-6 and MCP-1 in cultured human endothelial cells [16]. Moreover, the anti-inflammatory effects of CANA have also been suggested in lipopolysaccharide-stimulated coronary artery endothelial cells [15]. Furthermore, in the present study, the preservation of IR rings with CANA decreased nitrotyrosine immunoreactivity, suggesting reduced nitro-oxidative stress.

In the study of El-Daly et al., myocardial IRI was not associated with alteration in SGLT2 mRNA expression [26]. However, in response to high glucose, the expression of SGLT2 has been shown to decrease in the vasculature [26] and to increase in human renal tubular epithelial cells [27]. Indeed, T2DM is associated with upregulation of renal SGLT2 expression in murine and human kidney [28]. There is also evidence that SGLT2 is not involved in renal IRI, as shown by genetic deletion of SGLT2 in a murine model [29], whereas knock-out of SGLT1 protects against renal IRI [30]. Interestingly, the mRNA expression of SGLT1 was not changed in wild-type mice in IRI, compared with healthy controls. Although in the heart, SGLT2 is not expressed, knock-out of SGLT1 has been shown to reduce myocardial infarct size [31]. This class of drug may exert "off-target" cardiovascular benefits by modulating vascular endothelial cell activation and alleviating endothelial cell dysfunction. This is also supported by the work of Ange et al., who 
recently showed that CANA activates the alpha-1 AMPK-dependent pathway in human endothelial cells exposed to human septic plasma [32]. Furthermore, Behnammanesh et al. have demonstrated that CANA stimulates the expression of heme-oxygenase (HO)-1, a highly inducible antioxidant, in vascular smooth muscle cells. The induction of HO-1 by CANA requires ROS and is mediated by NF-E2-related factor (Nrf2), which contributes to its cellular actions [8]. Taken together, the ability of CANA to exert pleiotropic vascular protective effects suggests extra potential benefits.

It has been shown that blockade of CD40 ligand and its membrane receptor CD40's interactions prevent the development of vascular inflammation [33]. In line with these observations, we have shown that CANA prevented the upregulation of $C d 40$. Furthermore, we have demonstrated that in the rat aorta, mRNA expression levels for NoxO1, one of components forming NADPH oxidase (NOX)-1, was lowered in the IR + CANA group compared to the IR aortic rings. It is known that NOX and eNOS uncoupling are important vascular sources generating ROS, contributing to reduced NO production and endothelial dysfunction [34]. We recently showed that in vitro preincubation of aortic rings with CANA enhanced endothelium-dependent NO mediated vasorelaxation and increased sensitivity to ACh in nondiabetic, healthy rats [14]. A final point of discussion is that decreased contraction produced by high $\mathrm{KCl}$ in aortic rings was also augmented after CANA treatment. This result suggests that CANA restores cell membrane depolarization-induced contraction in smooth muscle cells. Additionally, an increased PE-induced contractile response was reduced by CANA, which could be related to improved endothelial function. SNP, an endothelium-independent vasodilator, fully relaxed aortic rings in all groups by direct effect on the smooth muscle cells. In the IR group treated with CANA, the concentrationrelaxation curves were shifted leftwards compared with the IR aortic rings. Altogether, these results suggest that CANA protects vascular smooth muscle cells against damage from IRI.

\subsection{Study Limitations}

The current study has some limitations that should be acknowledged. First, the role of surrounding tissues of the aorta, blood flow, and the activation of leukocytes need to be investigated in a relevant in vivo situation. Second, additional investigations are required to confirm the effects of IRI and CANA on human internal mammary artery and saphenous vein grafts in patients with and without T2DM undergoing CABG. Third, other relevant genes (such as Slc5a2), genes encoding major ion channels, and mitochondrial proteins were not investigated. Additionally, even though it is not common in clinical practice, storage at $4{ }^{\circ} \mathrm{C}$ for $24 \mathrm{~h}$ is a well-established in vitro vascular model for IRI. Finally, machine-learning analysis of gene expression dataset is a powerful new tool; however, a larger samples size is needed for a deep learning approach to predict diseases.

\section{Materials and Methods}

\subsection{Animals}

Three month old, nondiabetic male Wistar rats (Janvier Labs, Saint Berthevin, France) were housed under controlled temperature $\left(22 \pm 2{ }^{\circ} \mathrm{C}\right)$ and $12-12 \mathrm{~h}$ light-dark cycles rooms with ad libitum access to food and water, and acclimatized for at least 7 days prior to experiments. All animals received humane care in compliance with the 'Principles of Laboratory Animal Care', formulated by the National Society for Medical Research, and with the 'Guide for the Care and Use of Laboratory Animals', prepared by the Institute of Laboratory Animal Resources and published by the National Institutes of Health (NIH Publication, 8th Edition, 2011) with prior approval (on 5 April 2019) by the appropriate institutional review committees (T20/19). 


\subsection{Rat Model of Vascular IRI}

\subsubsection{Preparation of Aortic Rings}

The rats were euthanized with an overdose of sodium pentobarbital $(120 \mathrm{mg} / \mathrm{kg}$, intraperitoneally). The descending thoracic aorta was immediately explanted, carefully freed from periadventitial fat and connective tissue under an operation microscope, placed in a Petri dish containing either cold $\left(+4{ }^{\circ} \mathrm{C}\right)$ oxygenated Krebs-Henseleit solution (KHL) with the following composition (mM): $118 \mathrm{NaCl}, 4.7 \mathrm{KCl}, 1.2 \mathrm{KH}_{2} \mathrm{PO}_{4}, 1.2 \mathrm{MgSO}_{4}, 1.77 \mathrm{CaCl}_{2}$, $25 \mathrm{NaHCO}_{3}$ and 11.4 glucose, or cold physiological saline solution, and was cut into 4-mm long pieces.

\subsubsection{Conservation of Aortic Rings and Experimental Groups}

As previously described [35-37] the aortic rings were placed in test tubes containing physiological saline solution supplemented with either dimethyl sulfoxide (DMSO at $0.5 \%$ ) vehicle (IR group, $\mathrm{n}=28-40$ rings, $8-10$ rats) or $50 \mu \mathrm{M}$ CANA (IR + CANA group ( $\mathrm{n}=18-43$ rings, $9-11$ rats) and stored for $24 \mathrm{~h}$ at $4{ }^{\circ} \mathrm{C}$. To extrude oxygen, saline solution was previously gassed with nitrogen to adjust the partial pressure of oxygen $\left(\mathrm{pO}_{2}\right)$ to 70-74 mmHg. After cold ischemic conservation, the rings were mounted in organ baths. To mimic free radical generation and endothelial dysfunction, as occur during reperfusion and reoxygenation in vivo, sodium hypochlorite $(200 \mu \mathrm{M}, 30 \mathrm{~min})$ was added to the tissue chambers. Aortic rings in the control group ( $\mathrm{n}=26-40$ rings, $9-10$ rats) were immediately mounted in isolated tissue baths after preparation without cold ischemic storage and hypochlorite incubation. In the present study, $50 \mu \mathrm{M}$ canagliflozin was used, as the concentrations of $10-50 \mu \mathrm{M}$ reflects the clinical $C_{\max }(10 \mu \mathrm{M})$ employed in the animal experiments [5].

\subsubsection{Ex Vivo Organ Baths Functional Experiments}

As previously reported [38-40], each aortic ring was mounted on a stainless steel hook in an organ chamber containing $20 \mathrm{~mL}$ of KHL and continuously gassed with a mixture of $95 \% \mathrm{O}_{2}-5 \% \mathrm{CO}_{2}$, with temperature maintained at $37^{\circ} \mathrm{C}$ and $\mathrm{pH}$ at 7.4 (EMKA Technologies S.A.S, Paris, France). Initially, the tissue was equilibrated for $20 \mathrm{~min}$ at a resting tension before any experimental intervention. During an additional equilibration period of $60 \mathrm{~min}$, the passive tension was adjusted periodically to $2 \mathrm{~g}$ during which the baths were rinsed with fresh KHL every $30 \mathrm{~min}$ as a precaution against interfering metabolites. At the beginning of each experiment, a precontraction was achieved by adding $\mathrm{KCl}(80 \mathrm{mM})$ to organ baths to ensure tissue viability and to prepare the rings for stable contractions. After the contractile response had stabilized for approximately $30 \mathrm{~min}$, aortic rings were washed until resting tension was again restored. Then, the rings were contracted with an $\alpha$-adrenergic receptor agonist, $\mathrm{PE}\left(10^{-9}-10^{-5} \mathrm{M}\right)$ until a stable plateau was reached, and the relaxation responses were investigated by adding cumulative concentrations of endothelium-dependent vasorelaxant $\mathrm{ACh}\left(10^{-9}-10^{-4} \mathrm{M}\right)$. For testing relaxing responses of smooth muscle cells, an endothelium-independent dilator SNP $\left(10^{-10}-10^{-5} \mathrm{M}\right)$ was used in PE $\left(10^{-6} \mathrm{M}\right)$-precontracted aortic rings. Relaxation was expressed as a percent of the contraction induced by PE. Half-maximal response $\left(\mathrm{EC}_{50}\right)$ to PE, ACh, or SNP were determined from each individual concentration-response curve by sigmoidal fits using Origin 7.0 (Microcal Software, Northampton, Massachusetts, USA). The sensitivity $\mathrm{pD}_{2}$ $\left(-\log \mathrm{EC}_{50}\right)$ was then calculated.

\subsection{Gene Expression Analysis}

Using an $\mathrm{RT}^{2}$ Profiler PCR Array (Qiagen, Hilden, Germany), the expression of M involved in inflammation, apoptosis, and oxidative stress was profiled. The list of genes is presented in Table 3. As previously reported [41,42], total RNA was extracted from aorta samples using RNeasy Mini Kit (Qiagen, Hilden, Germany) and was reverse-transcribed into cDNA using the $\mathrm{RT}^{2}$ First Strand Kit, mixed with $\mathrm{RT}^{2}$ qPCR Master Mix containing SYBR Green, according to the manufacturer's instructions (Qiagen, Hilden, Germany). 
In this custom array, the following nonregulated genes (genes of interest) were used for normalization in the fold change expression data calculations: ribosomal protein lateral stalk subunit P1 (Rplp1), actine beta (ACTB), beta-2 microglobulin (B2m), hypoxanthineguanine phosphoribosyl transferase-1 (Hprt1), and lactate dehydrogenase A (Ldha). Genes at $p<0.05$ with fold regulation values greater than 2 or less than -2 indicate increased or decreased mRNA expression, respectively, and were considered significantly altered.

\subsection{Machine Learning Algorithms}

We used Boruta [43], a machine-learning method based on permutated random forest to identify non-linear correlations between gene expression and the study subgroups (Control/IR/IR + CANA). CrossBoruta uses the split probability (0-100\%) that an ensemble of decision trees will identify a specific pattern, and the "feature importance" (which resembles the effect size in traditional statistics) in combination with a stress majorization graph [44]. This method permits the exploration of nonlinear correlations across all genes, explaining the ability to reveal the underlying gene-gene interaction network. Finally, in our graph, the Spearman correlation is color-coded.

Table 3. Gene symbol and name.

\begin{tabular}{|c|c|}
\hline Name/Gene ID/Symbol & $\begin{array}{c}\text { Gene Name/Description } \\
\text { (for Rattus Norvegicus (=Wistar rat)) }\end{array}$ \\
\hline Aifm1 & apoptosis inducing factor, mitochondria associated 1 \\
\hline Apaf1 & apoptotic peptidase activating factor 1 \\
\hline Bad & BCL2-associated agonist of cell death \\
\hline Bak1 & BCL2-antagonist/killer 1 \\
\hline Bax & BCL2 associated X, apoptosis regulator \\
\hline$B c l 2$ & $B C L 2$, apoptosis regulator \\
\hline$B c l 2 L 1$ & Bcl2-like 1 \\
\hline Bid & $\mathrm{BH} 3$ interacting domain death agonist \\
\hline Casp1 & caspase 1 \\
\hline Casp12 & caspase 12 \\
\hline Casp3 & caspase 3 \\
\hline Casp4 & caspase 4 \\
\hline Casp6 & caspase 6 \\
\hline Casp7 & caspase 7 \\
\hline Casp8 & caspase 8 \\
\hline Casp9 & caspase 9 \\
\hline Cat & catalase \\
\hline Ccl11 & C-C motif chemokine ligand 11 \\
\hline Ccl12 & chemokine (C-C motif) ligand 12 \\
\hline $\mathrm{Ccl} 2$ & C-C motif chemokine ligand 2 \\
\hline Ccl20 & C-C motif chemokine ligand 20 \\
\hline $\mathrm{Ccl3}$ & C-C motif chemokine ligand 3 \\
\hline Ccl4 & C-C motif chemokine ligand 4 \\
\hline Ccl5 & C-C motif chemokine ligand 5 \\
\hline Cor1 & C-C motif chemokine receptor 1 \\
\hline Ccr2 & C-C motif chemokine receptor 2 \\
\hline
\end{tabular}


Table 3. Cont.

\begin{tabular}{|c|c|}
\hline Name/Gene ID/Symbol & $\begin{array}{c}\text { Gene Name/Description } \\
\text { (for Rattus Norvegicus (=Wistar rat)) }\end{array}$ \\
\hline Ccs & copper chaperone for superoxide dismutase \\
\hline$C d 40$ & CD40 molecule \\
\hline cd40lg & CD40 ligand \\
\hline Cflar & CASP8 and FADD-like apoptosis regulator \\
\hline $\mathrm{C} x \mathrm{Cr} 4$ & C-X-C motif chemokine receptor 4 \\
\hline Cyba & cytochrome b-245 alpha chain \\
\hline cycs & cytochrome c, somatic \\
\hline Duox1 & dual oxidase 1 \\
\hline$E d n 1$ & endothelin 1 \\
\hline$E p x$ & eosinophil peroxidase \\
\hline Fadd & Fas associated via death domain \\
\hline Fas & Fas cell surface death receptor \\
\hline Faslg & Fas ligand \\
\hline Flt1 & Fms related receptor tyrosine kinase 1 \\
\hline Fos & Fos proto-oncogene, AP-1 transcription factor subunit \\
\hline Gpx1 & glutathione peroxidase 1 \\
\hline Gpx2 & glutathione peroxidase 2 \\
\hline Gpx3 & glutathione peroxidase 3 \\
\hline Gpx4 & glutathione peroxidase 4 \\
\hline Gpx5 & glutathione peroxidase 5 \\
\hline Gpx6 & glutathione peroxidase 6 \\
\hline Gpx7 & glutathione peroxidase 7 \\
\hline Gstk1 & glutathione S-transferase kappa 1 \\
\hline Hspa1a & heat shock protein family A (Hsp70) member 1A \\
\hline Icam1 & intercellular adhesion molecule 1 \\
\hline Il10 & interleukin 10 \\
\hline Ill18 & interleukin 18 \\
\hline Illa & interleukin 1 alpha \\
\hline Illb & interleukin 1 beta \\
\hline Il6 & interleukin 6 \\
\hline Il7 & interleukin 7 \\
\hline Il9 & interleukin 9 \\
\hline Itgb2 & integrin subunit beta 2 \\
\hline Jun & Jun proto-oncogene, AP-1 transcription factor subunit \\
\hline Ncf1 & neutrophil cytosolic factor 1 \\
\hline$N f k b 1$ & nuclear factor kappa B subunit 1 \\
\hline Nos2 & nitric oxide synthase 2 \\
\hline Nox4 & NADPH oxidase 4 \\
\hline Noxo1 & NADPH oxidase organizer 1 \\
\hline
\end{tabular}


Table 3. Cont.

\begin{tabular}{|c|c|}
\hline Name/Gene ID/Symbol & $\begin{array}{c}\text { Gene Name/Description } \\
\text { (for Rattus Norvegicus (=Wistar rat)) }\end{array}$ \\
\hline $\operatorname{Prdx1}$ & peroxiredoxin 1 \\
\hline $\operatorname{Prd} x 2$ & peroxiredoxin 2 \\
\hline $\operatorname{Prd} x 3$ & peroxiredoxin 3 \\
\hline $\operatorname{Prd} x 4$ & peroxiredoxin 4 \\
\hline Sele & selectin E \\
\hline Slc5a1 & solute carrier family 5 member 1 \\
\hline Sod1 & superoxide dismutase 1 \\
\hline Sod2 & superoxide dismutase 2 \\
\hline Sod3 & superoxide dismutase 3 \\
\hline$T g f b 1$ & transforming growth factor, beta 1 \\
\hline Tlr1 & toll-like receptor 1 \\
\hline Tlr4 & toll-like receptor 4 \\
\hline $\operatorname{Tlr} 6$ & toll-like receptor 6 \\
\hline Tnf & tumor necrosis factor \\
\hline Tnfrsf12a & TNF receptor superfamily member $12 \mathrm{~A}$ \\
\hline Tollip & toll interacting protein \\
\hline Tp53 & tumor protein p53 \\
\hline Txn1 & thioredoxin 1 \\
\hline Txnrd1 & thioredoxin reductase 1 \\
\hline Txnrd2 & thioredoxin reductase 2 \\
\hline Vcam1 & vascular cell adhesion molecule 1 \\
\hline$V e g f c$ & vascular endothelial growth factor C \\
\hline Xiap & X-linked inhibitor of apoptosis \\
\hline
\end{tabular}

\subsection{Immunohistochemical Staining for ICAM-1, PECAM-1, Nitrotyrosine, and Caspase-3}

Immunohistochemistry was performed on buffered paraformaldehyde solution (4\%) fixed, paraffin embedded, distal regions of the aortic segments. Four- $\mu \mathrm{m}$ thick sections were cut with the Leica microtome (Leica Biosystems Nussloch GmbH, Nussloch, Germany) and placed on slides. Fifteen minutes of hydrogen peroxide (3\%) was used to prevent the endogenous peroxidase activity. To unmask the antigenic epitopes, the sections were pretreated in sodium citrate buffer $(\mathrm{pH}=6)$ for $20 \mathrm{~min}$ by heating in a microwave oven at $700 \mathrm{Watt}$, then blocked in $2 \%$ normal serum for $30 \mathrm{~min}$ at room temperature. After that, the sections were incubated overnight at $4{ }^{\circ} \mathrm{C}$ with mouse monoclonal IgG anti-ICAM-1 (1:100; abcam, Cambridge, UK), rabbit monolyclonal IgG anti-PECAM-1 (1:10,000; abcam, Cambridge, UK), mouse monolyclonal IgG2b anti-nitrotyrosine (1:1000; abcam, Cambridge, $\mathrm{UK})$, and rabbit polyclonal IgG anti-caspase-3 (1:100; antibodies-online $\mathrm{GmbH}$, Aachen, Germany) antibodies. The samples were then incubated for $30 \mathrm{~min}$ with a biotinylated secondary antibody diluted in serum buffer (1:50), and immunoreactivity was visualized using an avidin-biotinylated complex (ABC) reagent (VECTASTAIN universal elite ABC kit, Burlingame, CA, USA). Next, 3,3' diaminobenzidine (DAB substrate) was added to produce a brown-colored reaction product in the presence of horseradish peroxidase enzyme and used in double labeling applications (VECTOR DAB kit, Burlingame, CA, USA). During the last step, slide sections were cleared before mounting with ProTaqs Mount Aqua (Quartett, Berlin, Germany) and counterstained with haematoxylin. Digital images were captured using a conventional light microscope. Semiquantitative immunohistochemical analysis 
was performed with CellSens software (Olympus Soft Imaging Solutions GmbH, Germany) based on staining distribution patterns (along the endothelium for ICAM-1 and PECAM-1 or smooth muscle tissue for nitrotyrosine) and the intensity of the staining (score: 0-12). Nitrotyrosine content was determined by quantitative analysis using automated scoring with Image J plug-in IHC profiler. Evaluation from four randomized nonoverlapping fields of the aorta was done in a blinded fashion.

\subsection{Canagliflozin}

Canagliflozin $10 \mathrm{mM}$ (1 mL in DMSO) was bought from Selleck Chemicals (BIOZOL Diagnostica Vertrieb GmbH, Eching, Germany) and used at a final concentration of $50 \mu \mathrm{M}$.

\subsection{Data Analysis and Statistics}

The results are presented as the mean \pm standard error of the mean (SEM). Statistical analyses were performed using GraphPad Prism 7.02 software (GraphPad Software, Inc., CA, USA). For contractile responses to $\mathrm{KCl}$ and histological results. the Shapiro-Wilk normality test was used to assess normal distribution before statistical tests were applied. For data with normal distribution, one-way ANOVA and Tukey's post-hoc test were carried out for multiple comparisons. If the data were not normally distributed, the nonparametric Kruskal-Wallis test was used, followed by Dunn's post-hoc test. In cases of cumulative concentration-response curves to PE, Ach and SNP, a two-factor mixed ANOVA (factors: CANA and concentration of reagents (PE, ACh, SNP)) and a Tukey's post-hoc test were used for multiple comparisons. A $p<0.05$ was considered statistically significant. For the PCR array gene expression, $p$ values were calculated using a Student's t-test (two-tail distribution and equal or unequal variances between the two samples) with the average deltaCt value. Genes with arbitrary fold regulation cut-offs of $>2$-fold or $<-2$-fold at adjusted $p<0.05$ were considered to be significantly altered.

\section{Conclusions}

The addition of CANA to the preservation solution alleviates endothelial dysfunction following in vitro IRI in aortic rings from nondiabetic rats. CANA can exert its protective effects independent of glucose lowering and leucocyte engagement, at least in part, by lowering inflammatory response through reducing the expression of inflammatory molecule ICAM-1, increasing the expression of the endothelial marker PECAM-1 and the downregulation of proinflammatory genes Il1a, Il6a, NoxO1 and by preventing the upregulation of Cd40. Our machine learning approach predicted that Il1a, Il6a, cd40 and Icam 1 may be modified by CANA. From a clinical point of view, in patients undergoing CABG, IRI is the main contributor to tissue damage. It is tempting to speculate that the current study raises the possibility of repurposing this clinically approved antidiabetic drug, to be used during bypass surgery graft storage.

Author Contributions: Conceptualization, S.K.-I. and A.A.S.; Methodology, S.K.-I., A.A.S. and G.S.; Software, A.-I.G.; Validation, S.K.-I., A.A.S. and G.S.; Formal Analysis, S.K.-I., C.K., A.A.S. and A.-I.G.; Investigation S.K.-I., C.K., P.K., M.I.B. and S.A.; Resources, S.K.-I., M.K. and G.S.; Data curation; S.K.-I. and C.K.; Writing-Original Draft Preparation; S.K.-I. and A.A.S.; Writing-Review \& Editing; S.K.-I., C.K., A.A.S., A.-I.G., P.B., T.R., S.L., M.K. and G.S.; Visualization, S.K.-I., C.K. and A.A.S.; Supervision, S.K.-I. and G.S., Project Administration, S.K.-I., C.K., A.A.S. and G.S.; Funding Acquisition, S.K.-I., T.R., M.K. and G.S. All authors have read and agreed to the published version of the manuscript.

Funding: This study was supported by the Land Baden-Württemberg, Germany, by the Medical Faculty of the University of Heidelberg, Germany (to S. Korkmaz-Icöz). Project no. NVKP_16-1-20160017 ('National Heart Program') has been implemented with the support provided from the National Research, Development and Innovation Fund of Hungary, financed under the NVKP_16 funding scheme. The research was financed by the Thematic Excellence Program (2020-4.1.1.-TKP2020) of the Ministry for Innovation and Technology in Hungary, within the framework of the Therapeutic Development and Bioimaging thematic programs of the Semmelweis University. This project was 
supported by a grant from the National Research, Development and Innovation Office (NKFIH) of Hungary (K134939 to Tamás Radovits).

Institutional Review Board Statement: All animals received humane care in compliance with the 'Principles of Laboratory Animal Care', formulated by the National Society for Medical Research, and with the 'Guide for the Care and Use of Laboratory Animals', prepared by the Institute of Laboratory Animal Resources and published by the National Institutes of Health (NIH Publication, 8th Edition, 2011) and EU Directive 2010/63/EU with prior approval by the appropriate institutional review committees.

Informed Consent Statement: Not applicable.

Data Availability Statement: Data associated with this study is available upon reasonable request.

Acknowledgments: The expert technical assistance of Karin Sonnenberg, Lutz Hoffmann, and Tobias Mayer is gratefully acknowledged.

Conflicts of Interest: The authors declare no conflict of interest.

\section{References}

1. Carden, D.L.; Granger, D.N. Pathophysiology of ischaemia-reperfusion injury. J. Pathol. 2000, 190, 255-266. [CrossRef]

2. Harskamp, R.E.; Lopes, R.D.; Baisden, C.E.; de Winter, R.J.; Alexander, J.H. Saphenous vein graft failure after coronary artery bypass surgery: Pathophysiology, management, and future directions. Ann. Surg. 2013, 257, 824-833. [CrossRef]

3. Veres, G.; Hegedus, P.; Barnucz, E.; Schmidt, H.; Radovits, T.; Zoller, R.; Karck, M.; Szabo, G. TiProtec preserves endothelial function in a rat model. J. Surg. Res. 2016, 200, 346-355. [CrossRef]

4. Wilbring, M.; Tugtekin, S.M.; Zatschler, B.; Ebner, A.; Reichenspurner, H.; Matschke, K.; Deussen, A. Even short-time storage in physiological saline solution impairs endothelial vascular function of saphenous vein grafts. Eur. J. Cardiothorac. Surg. 2011, 40, 811-815. [CrossRef]

5. Tomlinson, B.; Hu, M.; Zhang, Y.; Chan, P.; Liu, Z.M. Evaluation of the pharmacokinetics, pharmacodynamics and clinical efficacy of empagliflozin for the treatment of type 2 diabetes. Expert Opin. Drug Metab. Toxicol. 2017, 13, 211-223. [CrossRef]

6. Devineni, D.; Curtin, C.R.; Polidori, D.; Gutierrez, M.J.; Murphy, J.; Rusch, S.; Rothenberg, P.L. Pharmacokinetics and pharmacodynamics of canagliflozin, a sodium glucose co-transporter 2 inhibitor, in subjects with type 2 diabetes mellitus. J. Clin. Pharmacol. 2013, 53, 601-610. [CrossRef] [PubMed]

7. Carbone, S.; Dixon, D.L. The CANVAS Program: Implications of canagliflozin on reducing cardiovascular risk in patients with type 2 diabetes mellitus. Cardiovasc. Diabetol. 2019, 18, 64. [CrossRef] [PubMed]

8. Perkovic, V.; Jardine, M.J.; Neal, B.; Bompoint, S.; Heerspink, H.J.L.; Charytan, D.M.; Edwards, R.; Agarwal, R.; Bakris, G.; Bull, S. Canagliflozin and renal outcomes in type 2 Diabetes and Nephropathy. N. Engl. J. Med. 2019, 380, 2295-2306. [CrossRef] [PubMed]

9. Neal, B.; Perkovic, V.; Mahaffey, K.W.; de Zeeuw, D.; Fulcher, G.; Erondu, N.; Shaw, W.; Law, G.; Desai, M.; Matthews, D.R. Canagliflozin and cardiovascular and renal events in type 2 Diabetes. N. Engl. J. Med. 2017, 377, 644-657. [CrossRef]

10. Packer, M.; Anker, S.D.; Butler, J.; Filippatos, G.; Pocock, S.J.; Carson, P.; Januzzi, J.; Verma, S.; Tsutsui, H.; Brueckmann, M.; et al. Cardiovascular and Renal Outcomes with Empagliflozin in Heart Failure. N. Engl. J. Med. 2020, 383, 1413-1424. [CrossRef] [PubMed]

11. McMurray, J.J.V.; Solomon, S.D.; Inzucchi, S.E.; Kober, L.; Kosiborod, M.N.; Martinez, F.A.; Ponikowski, P.; Sabatine, M.S.; Anand, I.S.; Belohlavek, J.; et al. Dapagliflozin in patients with heart failure and reduced ejection fraction. N. Engl. J. Med. 2019, 381, 1995-2008. [CrossRef]

12. Lim, V.G.; Bell, R.M.; Arjun, S.; Kolatsi-Joannou, M.; Long, D.A.; Yellon, D.M. SGLT2 Inhibitor, Canagliflozin, attenuates myocardial infarction in the diabetic and nondiabetic heart. JACC Basic Transl. Sci. 2019, 4, 15-26. [CrossRef]

13. Sayour, A.A.; Celeng, C.; Olah, A.; Ruppert, M.; Merkely, B.; Radovits, T. Sodium-glucose cotransporter 2 inhibitors reduce myocardial infarct size in preclinical animal models of myocardial ischaemia-reperfusion injury: A meta-analysis. Diabetologia 2021, 64, 737-748. [CrossRef] [PubMed]

14. Sayour, A.A.; Korkmaz-Icoz, S.; Loganathan, S.; Ruppert, M.; Sayour, V.N.; Olah, A.; Benke, K.; Brun, M.; Benko, R.; Horváth, E.M.; et al. Acute canagliflozin treatment protects against in vivo myocardial ischemia-reperfusion injury in non-diabetic male rats and enhances endothelium-dependent vasorelaxation. J. Transl. Med. 2019, 17, 127. [CrossRef] [PubMed]

15. Uthman, L.; Kuschma, M.; Romer, G.; Boomsma, M.; Kessler, J.; Hermanides, J.; Hollmann, M.W.; Preckel, B.; Zuurbier, C.J.; Weber, N.C. Novel anti-inflammatory effects of Canagliflozin involving Hexokinase II in Lipopolysaccharide-stimulated human coronary artery Endothelial cells. Cardiovasc. Drugs Ther. 2020. [CrossRef]

16. Mancini, S.J.; Boyd, D.; Katwan, O.J.; Strembitska, A.; Almabrouk, T.A.; Kennedy, S.; Palmer, T.M.; Salt, I.P. Canagliflozin inhibits interleukin-1beta-stimulated cytokine and chemokine secretion in vascular endothelial cells by AMP-activated protein kinase-dependent and -independent mechanisms. Sci. Rep. 2018, 8, 5276. [CrossRef] 
17. Rahadian, A.; Fukuda, D.; Salim, H.M.; Yagi, S.; Kusunose, K.; Yamada, H.; Soeki, T.; Sata, M. Canagliflozin prevents diabetesinduced vascular dysfunction in ApoE-deficient mice. J. Atheroscler. Thromb. 2020, 27, 1141-1151. [CrossRef] [PubMed]

18. Davis, C.; Fischer, J.; Ley, K.; Sarembock, I.J. The role of inflammation in vascular injury and repair. J. Thromb. Haemost. 2003, 1, 1699-1709. [CrossRef] [PubMed]

19. Khemais-Benkhiat, S.; Belcastro, E.; Idris-Khodja, N.; Park, S.H.; Amoura, L.; Abbas, M.; Auger, C.; Kessler, L.; Mayoux, E.; Toti, F.; et al. Angiotensin II-induced redox-sensitive SGLT1 and 2 expression promotes high glucose-induced endothelial cell senescence. J. Cell Mol. Med. 2020, 24, 2109-2122. [CrossRef] [PubMed]

20. Huang, P.L. Endothelial nitric oxide synthase and endothelial dysfunction. Curr. Hypertens Rep. 2003, 5, 473-480. [CrossRef]

21. Bagi, Z.; Frangos, J.A.; Yeh, J.C.; White, C.R.; Kaley, G.; Koller, A. PECAM-1 mediates NO-dependent dilation of arterioles to high temporal gradients of shear stress. Arterioscler. Thromb. Vasc. Biol. 2005, 25, 1590-1595. [CrossRef]

22. Newman, P.J. The biology of PECAM-1. J. Clin. Investig. 1997, 99, 3-8. [CrossRef] [PubMed]

23. Jevnikar, A.M.; Wuthrich, R.P.; Takei, F.; Xu, H.W.; Brennan, D.C.; Glimcher, L.H.; Rubin-Kelley, V.E. Differing regulation and function of ICAM-1 and class II antigens on renal tubular cells. Kidney Int. 1990, 38, 417-425. [CrossRef]

24. Koong, A.C.; Chen, E.Y.; Giaccia, A.J. Hypoxia causes the activation of nuclear factor kappa B through the phosphorylation of I kappa B alpha on tyrosine residues. Cancer Res. 1994, 54, 1425-1430. [PubMed]

25. Clark, P.R.; Manes, T.D.; Pober, J.S.; Kluger, M.S. Increased ICAM-1 expression causes endothelial cell leakiness, cytoskeletal reorganization and junctional alterations. J. Investig. Dermatol. 2007, 127, 762-774. [CrossRef] [PubMed]

26. El-Daly, M.; Pulakazhi Venu, V.K.; Saifeddine, M.; Mihara, K.; Kang, S.; Fedak, P.W.M.; Alston, L.A.; Hirota, S.A.; Ding, H.; Triggle, C.R. Hyperglycaemic impairment of PAR2-mediated vasodilation: Prevention by inhibition of aortic endothelial sodium-glucose-co-Transporter-2 and minimizing oxidative stress. Vascul. Pharmacol. 2018, 109, 56-71. [CrossRef]

27. Eleftheriadis, T.; Pissas, G.; Tsogka, K.; Nikolaou, E.; Liakopoulos, V.; Stefanidis, I. A unifying model of glucotoxicity in human renal proximal tubular epithelial cells and the effect of the SGLT2 inhibitor dapagliflozin. Int. Urol. Nephrol. 2020, 52, 1179-1189. [CrossRef]

28. Umino, H.; Hasegawa, K.; Minakuchi, H.; Muraoka, H.; Kawaguchi, T.; Kanda, T.; Tokuyama, H.; Wakino, S.; Itoh, H. High Basolateral Glucose Increases Sodium-Glucose Cotransporter 2 and Reduces Sirtuin-1 in renal tubules through Glucose Transporter-2 Detection. Sci. Rep. 2018, 8, 6791. [CrossRef]

29. Nespoux, J.; Patel, R.; Zhang, H.; Huang, W.; Freeman, B.; Sanders, P.W.; Kim, Y.C.; Vallon, V. Gene knockout of the Na(+)-glucose cotransporter SGLT2 in a murine model of acute kidney injury induced by ischemia-reperfusion. Am. J. Physiol. Renal Physiol. 2020, 318, F1100-F1112. [CrossRef]

30. Nespoux, J.; Patel, R.; Hudkins, K.L.; Huang, W.; Freeman, B.; Kim, Y.C.; Koepsell, H.; Alpers, C.E.; Vallon, V. Gene deletion of the $\mathrm{Na}(+)$-glucose cotransporter SGLT1 ameliorates kidney recovery in a murine model of acute kidney injury induced by ischemia-reperfusion. Am. J. Physiol. Renal Physiol. 2019, 316, F1201-F1210. [CrossRef]

31. Li, Z.; Agrawal, V.; Ramratnam, M.; Sharma, R.K.; D’Auria, S.; Sincoular, A.; Jakubiak, M.; Music, M.L.; Kutschke, W.J.; Huang, X.N. Cardiac sodium-dependent glucose cotransporter 1 is a novel mediator of ischaemia/reperfusion injury. Cardiovasc. Res. 2019, 115, 1646-1658. [CrossRef] [PubMed]

32. Ange, M.; De Poortere, J.; Ginion, A.; Battault, S.; Dechamps, M.; Muccioli, G.G.; Roumain, R.; Morelle, J.; Druart, S.; Mathivet, T. Canagliflozin protects against sepsis capillary leak syndrome by activating endothelial alpha1AMPK. Sci. Rep. 2021, 11, 13700. [CrossRef]

33. Hristov, M.; Gumbel, D.; Lutgens, E.; Zernecke, A.; Weber, C. Soluble CD40 ligand impairs the function of peripheral blood angiogenic outgrowth cells and increases neointimal formation after arterial injury. Circulation 2010, 121, 315-324. [CrossRef] [PubMed]

34. Brandes, R.P.; Weissmann, N.; Schroder, K. NADPH oxidases in cardiovascular disease. Free Radic. Biol. Med. 2010, 49, 687-706. [CrossRef] [PubMed]

35. Barnucz, E.; Veres, G.; Hegedus, P.; Klein, S.; Zoller, R.; Radovits, T.; Korkmaz, S.; Horkay, F.; Merkely, B.; Karck, M. Prolylhydroxylase inhibition preserves endothelial cell function in a rat model of vascular ischemia reperfusion injury. J. Pharmacol. Exp. Ther. 2013, 345, 25-31. [CrossRef]

36. Radovits, T.; Lin, L.N.; Zotkina, J.; Koch, A.; Rauen, U.; Kohler, G.; Karck, M.; Szabo, G. Endothelial dysfunction after long-term cold storage in HTK organ preservation solutions: Effects of iron chelators and N-alpha-acetyl-L-histidine. J. Heart Lung Transplant. 2008, 27, 208-216. [CrossRef]

37. Veres, G.; Hegedus, P.; Barnucz, E.; Zoller, R.; Radovits, T.; Korkmaz, S.; Kolonics, F.; Weymann, A.; Karck, M.; Szabo, G. Addition of vardenafil into storage solution protects the endothelium in a hypoxia-reoxygenation model. Eur. J. Vasc. Endovasc. Surg. 2013, 46, 242-248. [CrossRef]

38. Korkmaz, S.; Loganathan, S.; Mikles, B.; Radovits, T.; Barnucz, E.; Hirschberg, K.; Li, S.; Hegedus, P.; Pali, S.; Weymann, A.; et al. Nitric oxide- and heme-independent activation of soluble guanylate cyclase attenuates peroxynitrite-induced endothelial dysfunction in rat aorta. J. Cardiovasc. Pharmacol. Ther. 2013, 18, 70-77. [CrossRef]

39. Korkmaz-Icoz, S.; Radovits, T.; Loganathan, S.; Li, S.; Ruppert, M.; Benke, K.; Brlecic, P.; Szabo, C.; Karck, M.; Szabo, G. Prolonging hypothermic ischaemic cardiac and vascular storage by inhibiting the activation of the nuclear enzyme poly (adenosine diphosphate-ribose) polymerase. Eur. J. Cardiothorac. Surg. 2017, 51, 829-835. [CrossRef] 
40. Korkmaz-Icoz, S.; Vater, A.; Li, S.; Lehner, A.; Radovits, T.; Hegedus, P.; Ruppert, M.; Brlecic, P.; Zorn, M.; Karck, M. Mild type 2 diabetes mellitus improves remote endothelial dysfunction after acute myocardial infarction. J. Diabetes Complicat. 2015, 29, 1253-1260. [CrossRef]

41. Korkmaz-Icoz, S.; Li, S.; Huttner, R.; Ruppert, M.; Radovits, T.; Loganathan, S.; Sayour, A.A.; Brlecic, P.; Lasitschka, F.; Karck, M. Hypothermic perfusion of donor heart with a preservation solution supplemented by mesenchymal stem cells. J. Heart Lung Transplant. 2019, 38, 315-326. [CrossRef] [PubMed]

42. Korkmaz-Icoz, S.; Li, S.; Loganathan, S.; Radovits, T.; Ruppert, M.; Brlecic, P.; Sayour, A.A.; Veres, G.; Fleming, T.; Brune, M.; et al. Impairment of the Akt pathway in transplanted Type 1 diabetic hearts is associated with post-transplant graft injury. Interact. Cardiovasc. Thorac. Surg. 2018, 27, 884-894. [CrossRef] [PubMed]

43. Kursa, M.B.; Rudnicki, W.R. Feature Selection with the Boruta Package. J. Stat. Softw. 2010, 36, 13. [CrossRef]

44. Gansner, E.R.; Koren, Y.; North, S. Graph drawing by stress majorization. In International Symposium on Graph Drawing; Springer: Berlin/Heidelberg, Germany, 2004. 